\title{
Local proliferation maintains a stable pool of tissue-resident memory $T$ cells after antiviral recall responses
}

\author{
Simone L. Park', Ali Zaid ${ }^{1}{ }^{1}$, Jyh Liang Hor', Susan N. Christo', Julia E. Prier ${ }^{1}$, Brooke Davies', \\ Yannick O. Alexandre1, Julia L. Gregory', Tiffany A. Russell², Thomas Gebhardt ${ }^{1}{ }^{1}$, Francis R. Carbone', \\ David C. Tscharke $\mathbb{( D}^{2}$, William R. Heath ${ }^{1,3}{ }^{1,}$, Scott N. Mueller ${ }^{1,3 \star}$ and Laura K. Mackay ${ }^{1,3 \star}$
}

\begin{abstract}
Although tissue-resident memory $T$ cells $\left(T_{R M}\right.$ cells) are critical in fighting infection, their fate after local pathogen re-encounter is unknown. Here we found that skin $T_{R M}$ cells engaged virus-infected cells, proliferated in situ in response to local antigen encounter and did not migrate out of the epidermis, where they exclusively reside. As a consequence, secondary $\mathbf{T}_{\mathrm{RM}}$ cells formed from pre-existing $\mathbf{T}_{\mathrm{RM}}$ cells, as well as from precursors recruited from the circulation. Newly recruited antigen-specific or bystander $T_{R M}$ cells were generated in the skin without displacement of the pre-existing $T_{R M}$ cell pool. Thus, pre-existing skin $\mathbf{T}_{R M}$ cell populations are not displaced after subsequent infections, which enables multiple $T_{R M}$ cell specificities to be stably maintained within the tissue.
\end{abstract}

T RM cells are noncirculating lymphocytes that preferentially localize to sites of pathogen entry. $\mathrm{T}_{\mathrm{RM}}$ cells are critical mediators of antipathogen immunity and are becoming recognized as key players in cancer, autoimmune and allergic pathologies ${ }^{1,2}$. These cells exist in most organs and tissues in both humans and mice, and are found at high densities at sites of previous infection or inflammation ${ }^{3-5} \cdot \mathrm{T}_{\mathrm{RM}}$ cells are generated from precursors that are transiently present in the circulation, and they are phenotypically distinct from circulating memory $\mathrm{T}$ cells $\left(\mathrm{T}_{\mathrm{CIRCM}}\right.$ cells), with a unique transcriptional profile that is acquired during differentiation in the tissue ${ }^{6-9}$.

Their restricted anatomical localization and unique gene expression program enable $\mathrm{T}_{\mathrm{RM}}$ cells to mediate local immunosurveillance and rapid protection against reinfection. Local antigen-sensing by $\mathrm{T}_{\mathrm{RM}}$ cells can also result in the enhanced recruitment of both adaptive and innate circulating cells to the site of $\mathrm{T}_{\mathrm{RM}}$ cell activation ${ }^{10-12}$. However, surprisingly little is known regarding the fate of $T_{R M}$ cells after secondary pathogen encounter. It is not known whether $\mathrm{T}_{\mathrm{RM}}$ cells persist into secondary memory after recall responses, or whether pre-existing $T_{R M}$ cells are displaced by 'new' $T_{R M}$ cell populations generated after subsequent infections. It is also unclear whether reactivation of $\mathrm{T}_{\mathrm{RM}}$ cells can lead to re-entry into the recirculating pool.

Skin $T_{R M}$ cells persist in the epidermis, where they remain at the site of initial lodgment without diffusing through the tissue ${ }^{13,14}$. Skin $\mathrm{T}_{\mathrm{RM}}$ cells show minimal evidence of turnover in the steady state $^{15}$, depend uniquely on fatty acid metabolism ${ }^{16}$ and express molecules associated with inhibitory $\mathrm{T}$ cell function. Therefore, it might be expected that $T_{R M}$ cells are terminally differentiated and unable to expand and survive after recall. Here we examined the $\mathrm{T}_{\mathrm{RM}}$ cell response to secondary viral infection, using experimental approaches that enabled us to compare responses by $\mathrm{T}_{\mathrm{RM}}$ cells and
$\mathrm{T}_{\text {CIRCM }}$ cells. We used a model of herpes simplex virus type 1 (HSV) infection that infects the skin before entering the sensory ganglia, where it emerges via zositeriform spread as a band of lesions over the dermatome that is innervated by a single nerve ${ }^{17}$. $T_{R M}$ cells in the tissue can block peripheral HSV replication indirectly by affecting neuronal infection ${ }^{18}$. To determine whether skin-lodged $T_{R M}$ cells can control HSV directly at the skin surface, we reasoned that protection would be confined to regions of skin that contained an area, or 'patch', of embedded $\mathrm{T}_{\mathrm{RM}}$ cells. We show that in response to secondary viral infection, $\mathrm{T}_{\mathrm{RM}}$ cells mediated such local protection, engaged virus-infected cells, remained constrained to their epidermal niche and proliferated in situ. Skin $\mathrm{T}_{\mathrm{RM}}$ cells were maintained as a stable population after recall. Furthermore, we found that preexisting $\mathrm{T}_{\mathrm{RM}}$ cells were not displaced by newly recruited $\mathrm{T}_{\mathrm{RM}}$ cell populations, but instead remained as a numerically stable population in the tissue.

\section{Results}

Skin $T_{R M}$ cells mediate local immune protection. To understand how $\mathrm{T}_{\mathrm{RM}}$ cells directly control viral infection at the point of pathogen entry, we activated congenically marked $\mathrm{CD} 45.1^{+} \mathrm{CD} 8^{+}$gBT-I transgenic mouse $\mathrm{T}$ cells specific for the immunodominant determinant from HSV $\left(\mathrm{gB}_{498-505}\right)$ in vitro to generate effector $\mathrm{T}$ cells $\left(\mathrm{T}_{\mathrm{EFF}}\right.$ cells). We transferred the gBT-I $\mathrm{T}_{\mathrm{EFF}}$ cells intravenously (i.v.) into C57BL/6 mice and used the contact sensitizer dinitrofluorobenzene (DNFB) to recruit them into a patch of lower flank skin in a nonspecific manner ${ }^{19}$. This approach generates skin $\mathrm{T}_{\mathrm{RM}}$ cells at frequencies similar to that of the $\mathrm{gB}_{498-505}$-specific endogenous response induced by HSV infection but, importantly, leaves the sensory ganglia unpopulated by $\mathrm{T}$ cells. CD $45.1^{+}$gBT-I $\mathrm{T}_{\mathrm{RM}}$ cells expressing the surface markers CD69 and CD103 were present in DNFB-treated skin, but not in untreated contralateral skin (Supplementary Fig. 1a,b).

'Department of Microbiology and Immunology, The University of Melbourne and The Peter Doherty Institute for Infection and Immunity, Melbourne, VIC, Australia. ${ }^{2}$ John Curtin School of Medical Research, The Australian National University, Canberra, ACT, Australia. ${ }^{3}$ The Australian Research Council Centre of Excellence in Advanced Molecular Imaging, The University of Melbourne, Melbourne, VIC, Australia. Simone L. Park and Ali Zaid contributed equally to this work.Scott N. Mueller and Laura K. Mackay jointly supervised this work. *e-mail: smue@unimelb.edu.au; Ikmackay@unimelb.edu.au 
We inoculated the upper flank skin with $H S V>1 \mathrm{~cm}$ above the DNFB-treated patch containing gBT-I $\mathrm{T}_{\mathrm{RM}}$ cells to induce HSV replication and infection of the sensory ganglia (Supplementary Fig. 1c). Six days after HSV infection, a band of herpetic lesions spread across the dermatome from the point of inoculation, but the DNFB-treated skin patch remained clear of disease (Supplementary Fig. 1d). Viral titers 4 and $6 \mathrm{~d}$ after infection were reduced in DNFB-treated skin that contained gBT-I $\mathrm{T}_{\mathrm{RM}}$ cells compared with those in contralateral skin or in skin of mice treated with DNFB but not those given transfer of gBT-I T cells (Fig. 1a). Thus, $\mathrm{CD}^{+} \mathrm{T}_{\mathrm{RM}}$ cells can control HSV infection in the skin in a discrete and localized manner.

The density of skin $T_{\mathrm{RM}}$ cells influences local immune protection. After restimulation, $\mathrm{T}_{\mathrm{RM}}$ cells may facilitate enhanced recruitment of memory $\mathrm{T}$ cells from the circulation ${ }^{12}$. We examined whether this was the case after recall of DNFB-lodged skin $T_{R M}$ cells via HSV infection on the DNFB-untreated upper flank. We observed reduced recruitment of $\mathrm{CD} 103^{-} \mathrm{CD} 45.1^{+}$gBT-I T cells into DNFBtreated skin containing CD103+CD $45.1^{+}$gBT-I T ${ }_{\mathrm{RM}}$ cells $3-6 \mathrm{~d}$ after HSV infection compared with that in untreated skin that did not contain gBT-I $\mathrm{T}_{\mathrm{RM}}$ cells (Fig. 1b). This indicated that skin $\mathrm{T}_{\mathrm{RM}}$ cells were dominating local virus protection, in agreement with previous findings showing that $\mathrm{T}_{\mathrm{RM}}$ cells can protect in the absence of $\mathrm{T}_{\text {CIRCM }}$ cells $\mathrm{s}^{20-23}$. To assess whether this protective response requires an appropriate density of $\mathrm{T}_{\mathrm{RM}}$ cells to mediate protection, we transferred increasing numbers of Thy $1.1^{+}$gBT-I $\mathrm{T}_{\mathrm{EFF}}$ cells into mice and then subjected them to DNFB-mediated skin lodgment. We allowed the mice to rest for $>30 \mathrm{~d}$ and then injected them intraperitoneally (i.p.) with Thy1.1-specific antibody to deplete Thy1.1+ ${ }^{+}$BT-I $\mathrm{T}_{\text {CIRCM }}$ cells without affecting skin $\mathrm{T}_{\mathrm{RM}}$ cells ${ }^{20}$. Increasing the number of input Thy $1.1^{+}$gBT-I T cells resulted in a concomitant increase in the number of Thy1.1 $1^{+}$gBT-I $\mathrm{T}_{\mathrm{RM}}$ cells in DNFB-treated skin (Fig. 1c) and induced a dose-dependent reduction in viral load $6 \mathrm{~d}$ after HSV infection above the DNFB-treated skin patch (Fig. 1d). Thus, skin $\mathrm{T}_{\mathrm{RM}}$ cells mediate protection from infection in a manner dependent on their local density in the tissue and independent of circulating T cells.

Antigen-specific $\mathrm{T}_{\mathrm{RM}}$ cells exhibit dynamic responses to skin infection. To examine how skin $\mathrm{T}_{\mathrm{RM}}$ cells mediate protection after infection, we transferred in vitro-activated $\mathrm{EGFP}^{+}$gBT-I T cells into mice and then applied DNFB to induce skin lodgment. More than $30 \mathrm{~d}$ after $\mathrm{EGFP}^{+}$gBT-I T cell transfer, we imaged the DNFBtreated skin patch by intravital two-photon microscopy (IV-2PM) ${ }^{24}$. $\mathrm{EGFP}^{+}$gBT-I T cells had a dendritic morphology, showed slow migration, and were evenly distributed across the epidermal layer but absent from the dermis in a manner characteristic of skin $\mathrm{T}_{\mathrm{RM}}$ cells $^{13}$ (Fig. 2a). To determine whether skin $\mathrm{T}_{\mathrm{RM}}$ cells can respond to antigen in situ, $>30 \mathrm{~d}$ after $\mathrm{EGFP}^{+}$gBT-I T cell transfer and DNFB treatment, we delivered antigen directly into the epidermis by mixing HSV-derived gB peptide with aqueous sorbolene cream and applying it topically to depilated $\operatorname{skin}^{25}$. Starting at $3 \mathrm{~h}$ after gB peptide application, we observed changes in the dendritic morphology of skin $\mathrm{EGFP}^{+}$gBT-I $\mathrm{T}_{\mathrm{RM}}$ cells, which became more rounded with shorter dendrites and displayed reduced motility (Fig. 2b,c and Supplementary Video 1). In contrast, application of nonspecific ovalbumin (OVA) peptide did not alter the appearance or motility of skin $\mathrm{EGFP}^{+}$gBT-I T $_{\mathrm{RM}}$ cells (Fig. 2b,c and Supplementary Video 1), which indicates that epidermal $\mathrm{T}_{\mathrm{RM}}$ cells responded to cognate antigen in situ.

We next examined the localization and migration of $\mathrm{T}_{\mathrm{RM}}$ cells in DNFB-treated lower flank skin 3-4 d after infection of the DNFBuntreated upper flank skin with HSV-mCherry ${ }^{26}$. After zosteriform spread, we observed small epidermal foci of HSV-mCherry ${ }^{+}$ cells in DNFB-treated skin by $3.5 \mathrm{~d}$ after infection, and slow but noticeable spreading of mCherry ${ }^{+} \mathrm{HSV}$ over the 4-h imaging

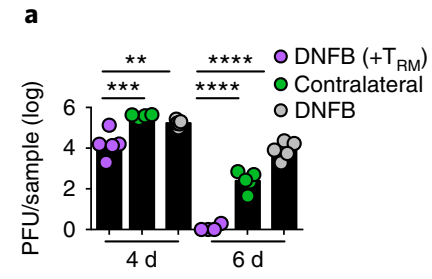

c

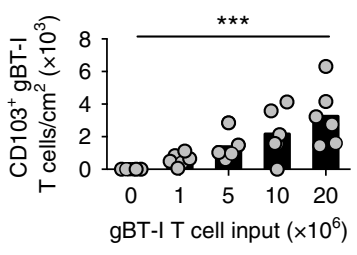

b

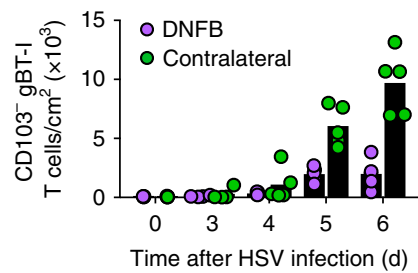

d

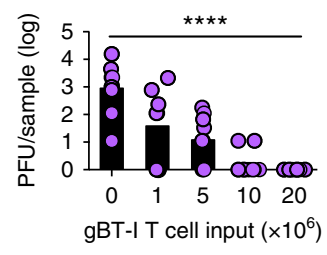

Fig. 1 | Antiviral protection by skin $T_{R M}$ cells correlates with $T_{R M}$ cell density. a, Skin HSV titers 4 and $6 \mathrm{~d}$ after HSV infection of the upper flank in mice that had previously received in vitro-activated gBT-I T cells and been treated with DNFB on the lower left flank. We analyzed DNFB-treated skin (DNFB $\left(+T_{R M}\right)$ ) or untreated skin from the right (contralateral) flank, as well as skin from DNFB-treated mice that did not receive gBT-I T cells (DNFB). ${ }^{\star \star} P=0.005,{ }^{\star \star \star} P=0.0004,{ }^{\star \star \star \star} P<0.0001$, one-way ANOVA with Tukey's multiple comparisons test. b. Enumeration of CD103- gBT-I T cells in DNFB-treated or contralateral skin after HSV infection. c, The number of $\mathrm{CD}_{103^{+}} \mathrm{T}_{\mathrm{RM}}$ cells in DNFB-treated skin of mice $>7 \mathrm{~d}$ after treatment with anti-Thy1.1. Mice received 0-20 $\times 10^{6}$ Thy $1.1^{+}$gBT-I $\mathrm{T}_{\text {EFF }}$ cells, were treated with DNFB, and were depleted of Thy $1.1^{+} \mathrm{T}_{\mathrm{CIRCM}}$ cells $>30 \mathrm{~d}$ later. ${ }^{\star \star \star} P=0.005$, Kruskal-Wallis test with Dunn's post-test. d, DNFB-treated skin HSV titers in the cohorts described in (c) $6 \mathrm{~d}$ after HSV infection. ${ }^{\star \star \star \star} P<0.0001$, Kruskal-Wallis test with Dunn's post-test. In all plots, bars represent mean values, and circles represent individual data points. Data are representative of two experiments with $n=4$ or 6 (a) or $n=3$ or 5 (b) mice per group per experiment, or are pooled from two experiments with $n=5$ or 6 (c) or $n=8$ or 10 (d) mice per group. PFU, plaque-forming units.

period (Supplementary Fig. 2a). $\mathrm{EGFP}^{+}$gBT-I T cells clustered near HSV-mCherry ${ }^{+}$infected cells, whereas epidermal cells distal to virus foci remained evenly distributed (Supplementary Fig. 2b). This suggested local accumulation of $\mathrm{EGFP}^{+}$gBT-I T cells in response to the virus, but without the possibility of distinguishing between $T_{R M}$ cells and $T$ cells recruited from the circulation. We also observed highly motile $\mathrm{EGFP}^{+}$gBT-I T cells in the underlying dermis (Fig. 2d and Supplementary Video 2). EGFP ${ }^{+}$ gBT-I T cells that engaged mCherry ${ }^{+} \mathrm{HSV}$-infected cells showed reduced motility and more restricted migration around the virus foci compared with that of $\mathrm{EGFP}^{+}$gBT-I T cells not recruited to foci of HSV-infected cells (Fig. 2e,f). Nonspecific EGFP+ OT-I $\mathrm{T}$ cells transferred to a second group of DNFB-treated mice as a control did not cluster in this manner after mCherry ${ }^{+} \mathrm{HSV}$ challenge (Fig. 2d and Supplementary Video 3). EGFP ${ }^{+}$OT-I $\mathrm{T}_{\mathrm{RM}}$ cells also retained their dendritic morphology, motility and epidermal localization after mCherry ${ }^{+}$HSV challenge (Fig. $2 \mathrm{~d}$ and Supplementary Video 3), which suggested that the changes in $T_{R M}$ cell behavior that we observed during viral recall depended on recognition of cognate antigen. To confirm this, we cotransferred equal numbers of activated $\mathrm{EGFP}^{+}$gBT-I T cells and lymphocyticchoriomeningitis-virus-specific DsRed ${ }^{+}$P14 T cells (from mice with transgenic expression of the P14 T cell antigen receptor specific for an epitope of lymphocytic choriomeningitis virus glycoprotein) into recipient mice and treated these mice with DNFB to generate skin $\mathrm{T}_{\mathrm{RM}}$ cells of alternative specificities on the lower flank. Thirty days later, we challenged the mice with $\mathrm{CFP}^{+} \mathrm{HSV}$ on the upper flank and imaged the DNFB-treated skin by IV-2PM. 
a

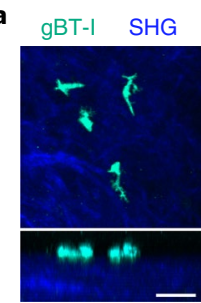

b

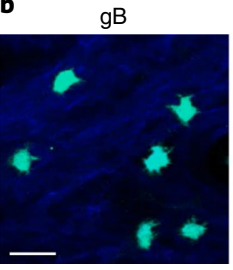

SHG gBT-I

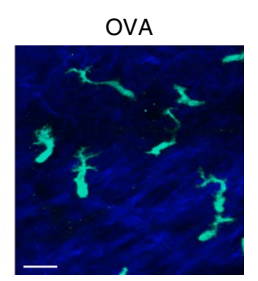

C
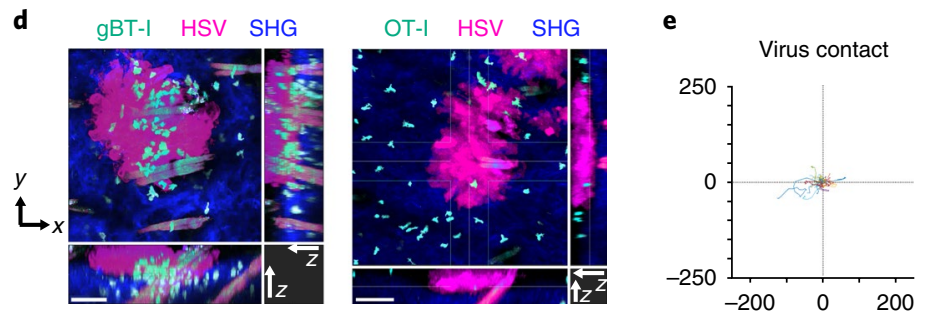

No virus contact
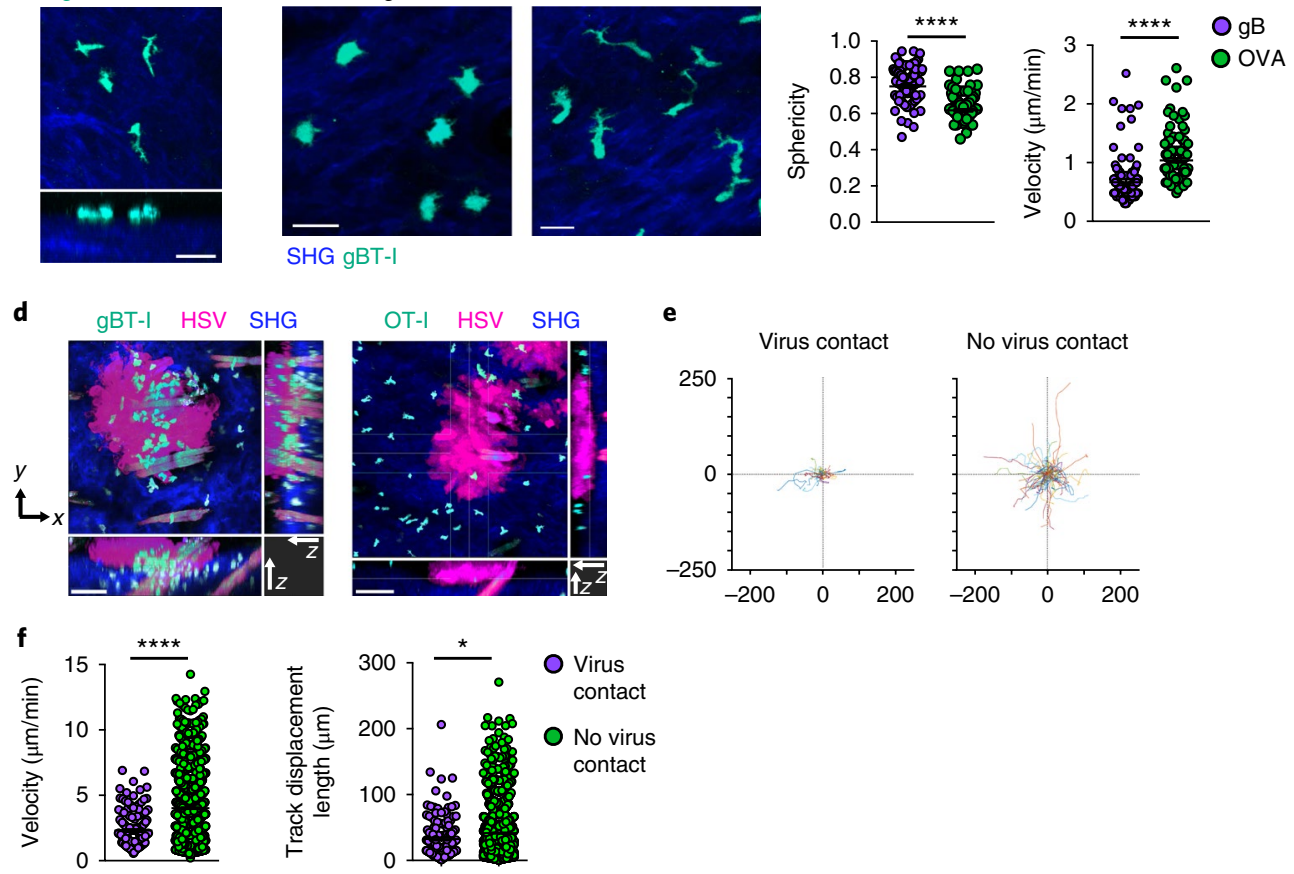

Fig. 2 | $T_{R M}$ cells respond in an antigen-specific manner after HSV challenge. a, An IV-2PM image of skin EGFP+ $g B T-I T_{R M}$ cells $>30$ d after DNFB treatment. b, IV-2PM images of EGFP+ skin $T_{\text {RM }}$ cells $3 \mathrm{~h}$ after $\mathrm{gB}$ or OVA peptide application. Scale bars, $20 \mu \mathrm{m}$ (a,b). c, Sphericity and velocity of skin $\mathrm{EGFP}^{+} \mathrm{gBT}-\mathrm{I} \mathrm{T}_{\mathrm{RM}}$ cells $3 \mathrm{~h}$ after $\mathrm{gB}$ or OVA peptide application. ${ }^{\star \star \star \star} \mathrm{P}<0.0001$, two-tailed Mann-Whitney U-test. d, Maximum-intensity projection images acquired $92-114 \mathrm{~h}$ after HSV-mCherry infection across $x, y$ and $z$ dimensions of skin containing DNFB-lodged EGFP+ $g B T-I$ or OT-I T cells. Scale bar, $60 \mu \mathrm{m}$ (left) or $75 \mu \mathrm{m}$ (right). e, Tracks of EGFP+ gBT-I T cell migration in the skin $94 \mathrm{~h}$ after HSV-mCherry infection in cells that did or did not make contact with HSV-mCherry ${ }^{+}$cells. f, Velocity and track displacement of EGFP+ $\mathrm{gBT}-\mathrm{I}$ T cells that did or did not come into contact with mCherry ${ }^{+}$virus-infected cells.

${ }^{\star} P=0.0137,{ }^{\star \star \star \star} P<0.0001$, two-tailed Mann-Whitney $U$-test. Data are representative of two experiments with $n=5$ or 6 mice per experiment $(\mathbf{a}, \mathbf{b})$ or four experiments (d) or are pooled from two experiments with $n=5$ or 6 mice per experiment (c) or from 5 mice from one of four representative experiments (e,f). SHG, second harmonic generation (dermal collagen). In $\mathbf{c}$ and $\mathbf{f}$, horizontal lines represent the mean, and circles represent individual cells.

$\mathrm{EGFP}^{+}$gBT-I $\mathrm{T}_{\mathrm{RM}}$ cells clustered and dynamically engaged $\mathrm{CFP}^{+}$ HSV-infected cells 3.5 d after infection, whereas DsRed ${ }^{+}$P14 T cells did not (Supplementary Fig. 2c). Thus, local HSV infection drove dynamic responses by skin $\mathrm{T}_{\mathrm{RM}}$ cells that were dependent on antigen-specific signals.

Skin $T_{R M}$ cell responses are epidermally constrained during recall. We next asked whether epidermal $\mathrm{T}_{\mathrm{RM}}$ cells can migrate toward foci of infected keratinocytes as well as into the underlying dermis. To distinguish between gBT-I $\mathrm{T}_{\mathrm{RM}}$ cells and gBT-I T cells recruited from the circulation, we used mice with DNFB-lodged Thy $1.1^{+} \mathrm{EGFP}^{+}$gBT-I $\mathrm{T}_{\mathrm{RM}}$ cells and, $>30 \mathrm{~d}$ after DNFB treatment, treated them with anti-Thy1.1 to selectively remove Thy $1.1^{+}$gBT-I $\mathrm{T}_{\text {CIRCM }}$ cells. Ten days after antibody treatment, we infected the mice with HSV-mCherry above the DNFB-treated skin, and $4 \mathrm{~d}$ after that we imaged them by IV-2PM. EGFP ${ }^{+}$gBT-I $\mathrm{T}_{\mathrm{RM}}$ cells in the $\mathrm{mCherry}^{+}$virus foci adopted a rounded morphology and were more sessile than nearby EGFP ${ }^{+} \mathrm{T}_{\mathrm{RM}}$ cells that were not in contact with virus-infected cells (Fig. 3a,b and Supplementary Video 4). Although we observed highly motile dermal EGFP ${ }^{+}$gBT-I T cells in undepleted mice (Fig. 2d and Supplementary Video 2), we did not observe $\mathrm{EGFP}^{+}$gBT-I T cells in the dermis of anti-Thy1.1-treated mice (Fig. $3 \mathrm{c}$ ), which indicates that $\mathrm{T}_{\mathrm{RM}}$ cells responding to challenge within the epidermis did not transit into the dermis.

Next, we directly compared the recall responses of DNFBlodged $\mathrm{T}_{\mathrm{RM}}$ cells with those mediated by memory $\mathrm{T}$ cells recruited from the circulation. To do this, we generated DNFB-recruited skin $\mathrm{T}_{\mathrm{RM}}$ cells by using gBT-I T cells expressing the photoconvertible protein Kaede, which changes from green fluorescent
(Kaede-green) to red fluorescent (Kaede-red) upon exposure to violet light ${ }^{27}$. We infected mice with HSV-CFP above DNFBtreated skin, and $2 \mathrm{~d}$ later we exposed the DNFB-treated skin patch to violet light to create Kaede-red ${ }^{+}$epidermal $\mathrm{T}_{\mathrm{RM}}$ cells, while unconverted gBT-I T cells in the circulation remained Kaedegreen $^{+}$. After the spread of HSV to the lower skin flank, on day 3.5 , both Kaede-red ${ }^{+}$and Kaede-green ${ }^{+}$gBT-I T cells accumulated around $\mathrm{CFP}^{+}$HSV foci (Fig. 3d). Kaede-red ${ }^{+}$gBT-I T cells that were distal to virus remained evenly distributed and localized to the epidermis, with a lower average velocity compared with that of the predominantly Kaede-green ${ }^{+}$gBT-I T cells in the dermis (Fig. 3e). To assess whether $\mathrm{T}_{\mathrm{RM}}$ cells migrate from skin to lymph nodes during the recall response, we next examined the distribution of photoconverted and unconverted gBT-I T cells in the skin and draining axillary lymph node $4-5 \mathrm{~d}$ after infection with HSV. The majority $(91 \% \pm 4.6 \%)$ of gBT-I T cells in the skin $4 \mathrm{~d}$ after HSV infection were Kaede-red ${ }^{+}$(Fig. 3f,g), which indicated that these cells were resident in the skin before viral spread. On day 5 after infection, we observed a greater proportion $(34 \% \pm 25 \%)$ of Kaede-green ${ }^{+}$gBT-I T cells in the skin (Fig. $3 g$ ), which indicated recruitment of gBT-I T cells from the circulation. Notably, we could not detect Kaede-red ${ }^{+}$gBT-I T cells in the draining lymph node at either time point after infection (Fig. $3 \mathrm{~g}$ ). Moreover, the Kaede-red ${ }^{+}$gBT-I T cells retained a CD103 ${ }^{+} \mathrm{CD} 69^{+}$ $\mathrm{T}_{\mathrm{RM}}$ cell phenotype, distinct from that of Kaede-green ${ }^{+}$gBT-I T cells, which were $\mathrm{CD} 103^{-} \mathrm{CD} 69^{-}$(Fig. 3h,i). Together, these data indicate that skin $\mathrm{T}_{\mathrm{RM}}$ cells that responded to recall virus infection remained constrained to the epidermis and did not migrate into the dermis or local draining lymph nodes. 
$T_{\mathrm{RM}}$ cells proliferate locally in response to antigenic challenge. Phenotypic flow cytometry analysis of gBT-I $\mathrm{T}_{\mathrm{RM}}$ cells isolated from previously challenged skin $>30 \mathrm{~d}$ after HSV infection or DNFB treatment showed increased surface expression of multiple coinhibitory molecules, including PD-1, Tim-3, LAG3, CD101, CD244, CTLA4

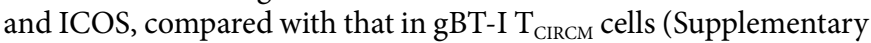
Fig. 3a,b). Because these inhibitory receptors are involved in the inhibition of $\mathrm{T}$ cell proliferation and effector functions ${ }^{28}$, we tested whether skin $\mathrm{T}_{\mathrm{RM}}$ cell populations could undergo substantial numerical expansion after challenge. To this end, we generated mice with DNFB-lodged Thy1.1 ${ }^{+}$gBT-I $\mathrm{T}_{\mathrm{RM}}$ cells and treated them after $>30 \mathrm{~d}$ either with anti-Thy1.1 to deplete gBT-I $\mathrm{T}_{\text {CIRCM }}$ cells or with PBS as a control. After infecting mice with HSV above DNFBtreated skin, we treated them i.p. with bromodeoxyuridine (BrdU) to assess the proliferative capacity of lodged $\mathrm{T}_{\mathrm{RM}}$ cells responding to HSV spread (Supplementary Fig. 4a). Seven days after HSV infection, we detected a population of circulating CD103- $\mathrm{gBT}-\mathrm{I}$ T cells in the DNFB-treated skin of non-antibody-treated control mice, whereas we detected only CD103 ${ }^{+} \mathrm{T}_{\mathrm{RM}}$ cells in DNFB-treated skin of anti-Thy1.1-treated mice (Fig. 4a). Notably, a substantial proportion $(36 \% \pm 5.4 \%)$ of $\mathrm{CD} 103^{+}$gBT-I $\mathrm{T}_{\mathrm{RM}}$ cells from the skin of Thy1.1-depleted mice had incorporated BrdU $7 \mathrm{~d}$ after infection (Fig. 4b,c). The proliferation marker Ki67 was also upregulated by skin $\mathrm{gBT}-\mathrm{I} \mathrm{T}_{\mathrm{RM}}$ cells after infection (Fig. $4 \mathrm{~b}$ and Supplementary Fig. $4 \mathrm{~b}$ ), which indicates that skin $\mathrm{T}_{\mathrm{RM}}$ cells proliferated in situ after rechallenge. Ki67 was also upregulated by gBT-I T cells in the spleens of PBS-treated controls after HSV infection (Supplementary Fig. 4c). Divided BrdU ${ }^{+}$gBT-I $\mathrm{T}_{\mathrm{RM}}$ cells in DNFB-treated skin of Thy1.1-depleted mice remained $\mathrm{CD} 103^{+} 7 \mathrm{~d}$ after HSV infection (Supplementary Fig. $4 \mathrm{~d}$ ), which suggests that $\mathrm{T}_{\mathrm{RM}}$ cell proliferation expanded or maintained the epidermal $\mathrm{T}_{\mathrm{RM}}$ cell pool, and that $\mathrm{T}_{\mathrm{RM}}$ cells did not give rise to CD103- T cells or lose CD103 expression after stimulation. In a separate approach, we induced skin gBT-I $\mathrm{T}_{\mathrm{RM}}$ cells from adoptively transferred Thy $1.1^{+}$gBT-I naive $\mathrm{T}$ cells
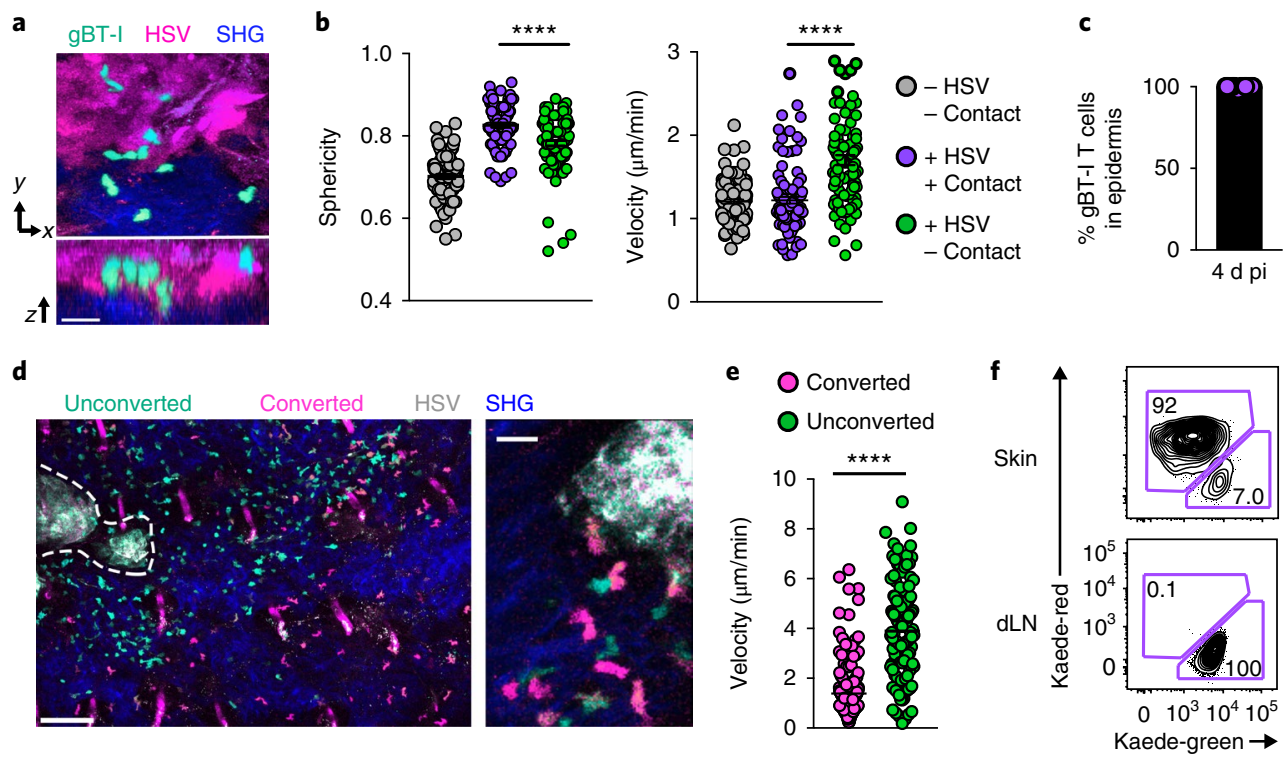

$\mathbf{g}$

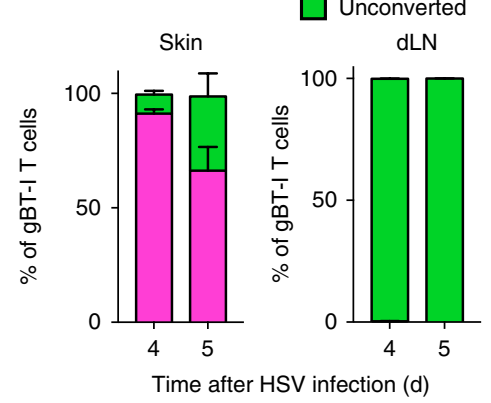

h

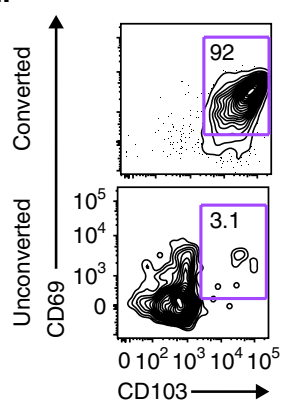

i
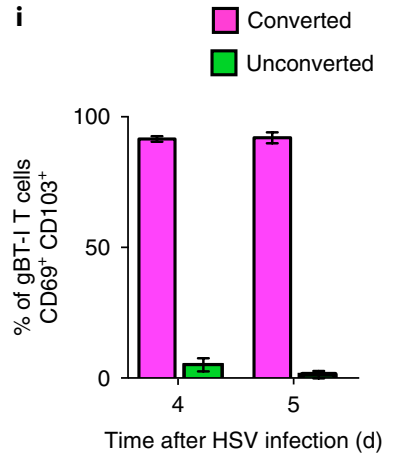

Fig. 3 | Skin $T_{R M}$ cells remain localized to the epidermis after virus rechallenge. a, An IV-2PM image of EGFP+Thy $1.1^{+} T_{R M}$ cells entering HSV-mCherry ${ }^{+}$ virus foci in DNFB-treated skin of $\mathrm{T}_{\mathrm{CIRCM}}$-cell-depleted mice $4 \mathrm{~d}$ after HSV infection. Scale bar, $30 \mu \mathrm{m}$. $\mathbf{b}$, Sphericity and velocity of EGFP+Thy $1.1^{+} \mathrm{gBT}$-I $\mathrm{T}_{\mathrm{RM}}$ cells in cells in contact (or not) with mCherry ${ }^{+}$cells $4 \mathrm{~d}$ after HSV-mCherry infection. ${ }^{\star \star \star \star} P<0.0001$, two-tailed Mann-Whitney U-test. c, The percentage of EGFP+Thy1.1+ gBT-I T $T_{\text {RM }}$ cells localizing to the epidermis of DNFB-treated skin $4 \mathrm{~d}$ after HSV-mCherry infection. pi, post-infection. d, IV-2PM images of $K_{\text {Kaede }} \mathrm{gBT}_{-1} \mathrm{~T}_{\mathrm{RM}}$ cells in DNFB-treated skin $3.5 \mathrm{~d}$ after HSV-CFP infection above the DNFB patch and $2 \mathrm{~d}$ after exposure to violet light. White dashed lines represent foci of virus-infected cells. Scale bars, $100 \mu \mathrm{m}$ (left) or $20 \mu \mathrm{m}$ (right). e, The velocity of Kaede-green ${ }^{+}$(unconverted) and Kaede-red ${ }^{+}$(converted) gBT-I T cells in DNFB-treated skin $3.5 \mathrm{~d}$ after HSV-CFP infection and $2 \mathrm{~d}$ after exposure to violet light. ${ }^{\star \star \star \star} P<0.0001$, two-tailed Mann-Whitney U-test. f-i, Results of flow cytometry showing Kaede ${ }^{+} \mathrm{gBT}-\mathrm{I}$ T cell fluorescence phenotypes in DNFB-treated skin and draining axillary lymph node (dLN) 4-5 d after HSV infection and $2 \mathrm{~d}$ after exposure to violet light. $\mathbf{f}, \mathbf{g}$, The proportion of converted or unconverted Kaede ${ }^{+}$gBT-I T cells localizing to skin or dLN. $\mathbf{h}, \mathbf{i}$, Expression of CD69 and CD103 among converted and unconverted Kaede ${ }^{+}$gBT-I T cells. In $\mathbf{f}$ and $\mathbf{h}$, numbers adjacent to outlines indicate the percentage of cells in the gate. SHG, second harmonic generation. Data shown are representative of 7 mice from two experiments (a), three experiments with $n=3$ mice per experiment (d,e), or two experiments with $n=6$ mice per experiment $(\mathbf{f}-\mathbf{i})$ or are pooled from two experiments with $n=14$ movies from 7 mice $(\mathbf{b}, \mathbf{c}) .(\mathbf{c}, \mathbf{g}, \mathbf{i})$ Data are shown as the mean \pm s.e.m. $(\mathbf{b}, \mathbf{e})$ Horizontal lines represent the mean, and circles represent individual cells. 

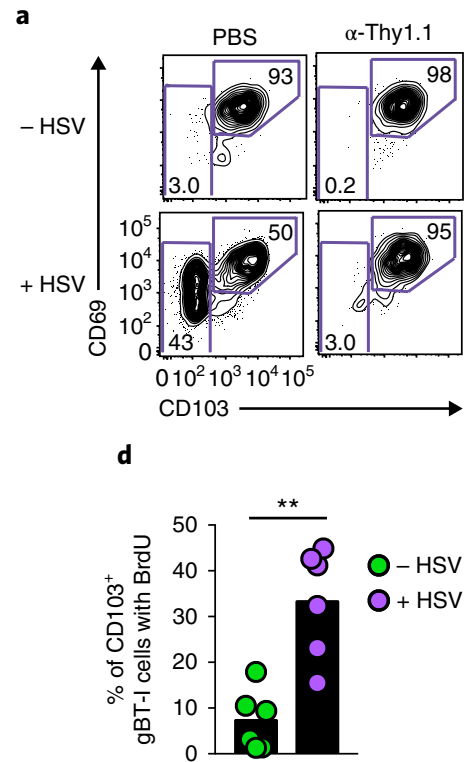

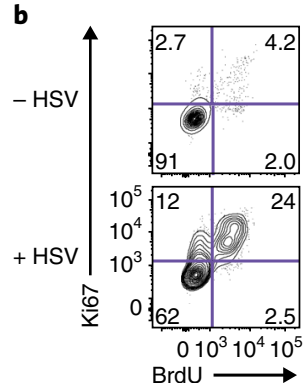

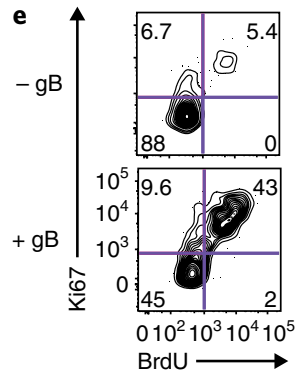

$\mathbf{f}$

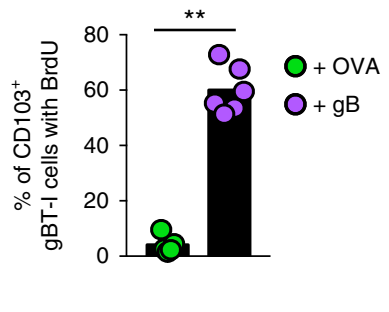

Fig. 4 | $\mathbf{T}_{\mathrm{RM}}$ cells proliferate after antigenic challenge. a, CD69 and CD103 expression by skin Thy1.1+ gBT-I $\mathrm{T}_{\mathrm{RM}}$ cells $7 \mathrm{~d}$ after infection in anti-Thy1.1treated and PBS-treated (control) cohorts. Numbers adjacent to outlines indicate the percentage of cells in the gate. $\mathbf{b}$, Representative BrdU and Ki67

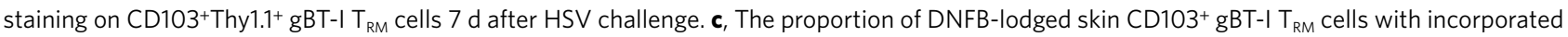
$\mathrm{BrdU}$ in mice $>7 \mathrm{~d}$ after HSV infection and in noninfected mice, determined by the Overton method of population comparison. ${ }^{\star \star} P=0.0022(-\alpha-T h y 1.1)$, ${ }^{\star \star} P=0.0047$ ( $+\alpha$-Thy1.1), two-tailed Mann-Whitney U-test. d, The proportion of VV-gB-infected lodged skin CD103+Thy1.1+ gBT-I T ${ }_{\text {RM }}$ cells with incorporated BrdU in mice $>7 \mathrm{~d}$ after HSV infection and in noninfected mice. ${ }^{\star \star} P=0.0043$, two-tailed Mann-Whitney $U$-test. e, Representative BrdU and Ki67 staining on CD103+Thy $11^{+}$gBT-I T RM cells $2 \mathrm{~d}$ after HSV-gB peptide application. In $\mathbf{b}$ and $\mathbf{e}$, numbers in corners indicate the percentage of cells in each quadrant. f, The proportion of skin CD103+Thy $1.1^{+}$gBT-I $\mathrm{T}_{\mathrm{RM}}$ cells with incorporated BrdU $2 \mathrm{~d}$ after topical HSV-gB or OVA peptide application, as determined by the Overton method of population comparison. ${ }^{\star \star} P=0.0043$, two-tailed Mann-Whitney $U$-test. (c,d,f) Bars represent the mean, and symbols represent individual mice. Data are representative of two experiments with $n=3$ or 4 mice per group (a,b,e) or are pooled from two experiments with $n=6$ or 8 mice per group (c), $n=6$ mice per group (d) or $n=5-7$ mice per group (f).

$\left(\mathrm{T}_{\mathrm{N}}\right.$ cells) by epicutaneous skin infection on the lower flank with recombinant vaccinia virus (VV) expressing the HSV gB epitope (VV-gB). After $30 \mathrm{~d}$ we treated the mice with anti-Thyl.1 to deplete Thy $1.1^{+}$gBT-I $\mathrm{T}_{\text {CIRCM }}$ cells, and $>7 \mathrm{~d}$ after that we infected them with HSV above the primary VV infection site and subsequently treated them with BrdU (Supplementary Fig. 4a). We observed increased BrdU incorporation by skin Thy $1.1^{+}$gBT-I $\mathrm{T}_{\mathrm{RM}}$ cells $(33.3 \% \pm 4.8 \%)$ compared with that in uninfected mice $(7.3 \% \pm 2.7 \%)$, which indicates that virally primed $\mathrm{T}_{\mathrm{RM}}$ cells also divide after rechallenge (Fig. 4d). We also assessed the uptake of BrdU by gBT-I $\mathrm{T}_{\mathrm{RM}}$ cells $2 \mathrm{~d}$ after transcutaneous application of HSV-gB peptide (Fig. 4e). $\mathrm{T}_{\mathrm{RM}}$ cells induced by DNFB recruitment or local HSV infection showed similar proliferative responses $(45 \% \pm 15 \%$ or $42 \% \pm 6.6 \%$ $\mathrm{BrdU}^{+}$, respectively) in response to $\mathrm{HSV}-\mathrm{gB}$ peptide application (Supplementary Fig. 4e). Finally, we tested whether skin gBT-I $T_{R M}$ cell proliferation was antigen specific by applying HSV-gB peptide or a nonspecific OVA peptide to the skin of DNFB-treated mice that had also been treated with BrdU, and we observed that division of skin Thy1.1 ${ }^{+}$gBT-I $\mathrm{T}_{\mathrm{RM}}$ cells occurred only in response to cognate antigen (Fig. 4f). Together, these observations indicated that skin $\mathrm{T}_{\mathrm{RM}}$ cells were not terminally differentiated and divided in situ in response to viral challenge.

However, compared with numbers in uninfected mice, we observed only a marginal increase in the number of Thy $1.1^{+}$gBT-I $\mathrm{T}_{\mathrm{RM}}$ cells in DNFB-treated skin between 3 and $14 \mathrm{~d}$ after HSV infection of skin above the DNFB patch (Supplementary Fig. 4f). Among the rechallenged gBT-I $\mathrm{T}_{\mathrm{RM}}$ cell population, we observed an increase in the proportions of annexin $\mathrm{V}^{+}$(from $8.5 \% \pm 0.7 \%$ to $18 \% \pm 2.2 \%$ ) and annexin $\mathrm{V}^{+} \mathrm{PI}^{+}$cells (from $7 \% \pm 0.7 \%$ to $11 \% \pm 0.9 \%$ ) $7 \mathrm{~d}$ after HSV infection compared with that of DNFB-lodged gBT-I $\mathrm{T}_{\mathrm{RM}}$ cells at steady state (Supplementary Fig. 4f,g), indicative of increased apoptosis of $\mathrm{T}_{\mathrm{RM}}$ cells after recall in addition to heightened proliferation. In all, these data indicate that $\mathrm{T}_{\mathrm{RM}}$ cells can be maintained by local proliferation during secondary infections, without the requirement for replenishment from the circulating $\mathrm{T}$ cell pool.

Circulating $T$ cells form new $T_{R M}$ cells without displacing preexisting $\mathbf{T}_{\mathrm{RM}}$ cells. Next, we examined whether antigen-specific memory $\mathrm{T}$ cells in the circulation are recruited to inflamed skin and develop into $\mathrm{T}_{\mathrm{RM}}$ cells after secondary challenge. We also asked how these incoming cells might affect populations of pre-existing $\mathrm{T}_{\mathrm{RM}}$ cells in the skin. To this end, we carried out antibody-mediated enrichment of $\mathrm{CD}_{4} 4^{+} \mathrm{CD} 45.1^{+}$gBT-I $\mathrm{T}_{\mathrm{CIRCM}}$ cells isolated from spleens of mice that were previously infected with HSV, and transferred them into anti-Thy1.1-treated recipient mice with DNFBlodged Thy1.1 ${ }^{+}$gBT-I skin $\mathrm{T}_{\mathrm{RM}}$ cells. Two days after CD45.1 ${ }^{+}$gBT-I $\mathrm{T}_{\text {CIRCM }}$ cell transfer, we infected the recipient mice with HSV above DNFB-treated skin to restimulate both skin $\mathrm{T}_{\mathrm{RM}}$ cells and adoptively transferred $\mathrm{T}_{\text {CIRCM }}$ cells (Supplementary Fig. 5a). We detected CD45.1 ${ }^{+}$gBT-I $\mathrm{T}_{\text {CIRCM }}$ cells in DNFB-treated skin alongside Thy $1.1^{+}$ gBT-I $T_{R M}$ cells and observed that these cells persisted for at least $30 \mathrm{~d}$ after HSV infection (Fig. 5a,b). CD45.1 ${ }^{+}$gBT-I $\mathrm{T}_{\text {CIRCM }}$ cells that infiltrated the skin upregulated both CD69 and CD103 (Fig. 5c), indicative of de novo $\mathrm{T}_{\mathrm{RM}}$ cell formation from circulating memory $\mathrm{T}$ cell precursors. Stable numbers of Thy1.1 $1^{+}$gBT-I $\mathrm{T}_{\mathrm{RM}}$ cells were maintained in the DNFB-treated skin before and after HSV challenge, irrespective of CD45.1 ${ }^{+}$gBT-I $\mathrm{T}_{\text {CIRCM }}$ transfer (Fig. 5b), which indicates that the pre-existing skin $\mathrm{T}_{\mathrm{RM}}$ cell population was not displaced by subsequent $\mathrm{T}_{\mathrm{RM}}$ cell generation. Together, these findings indicate that both local maintenance of pre-existing $\mathrm{T}_{\mathrm{RM}}$ cells and de 
a

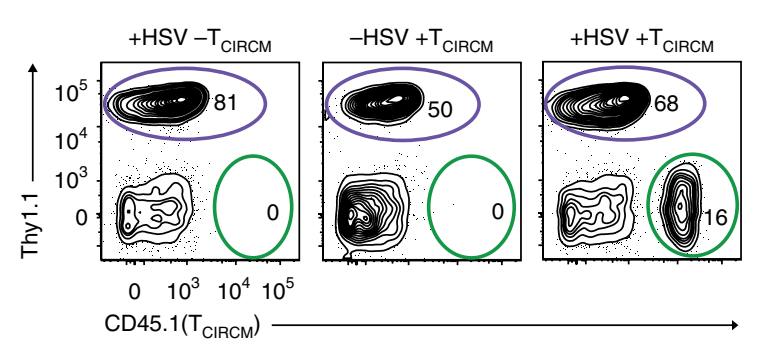

b

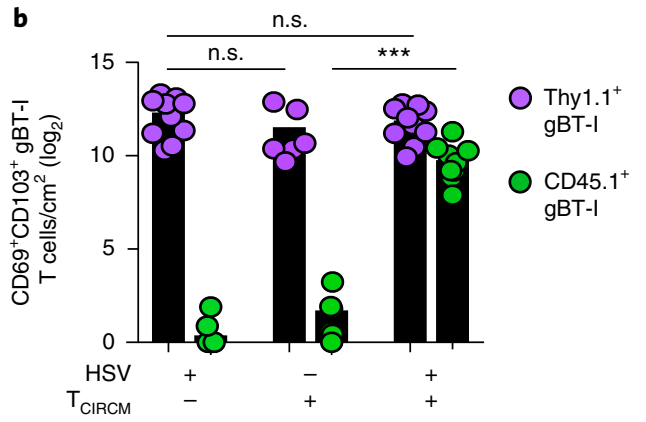

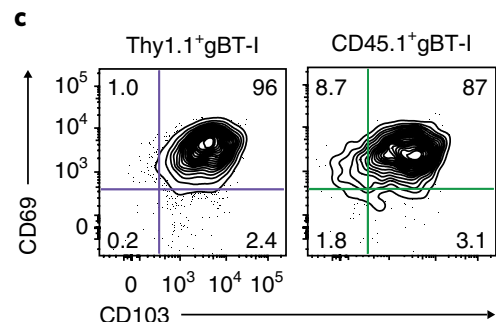

e

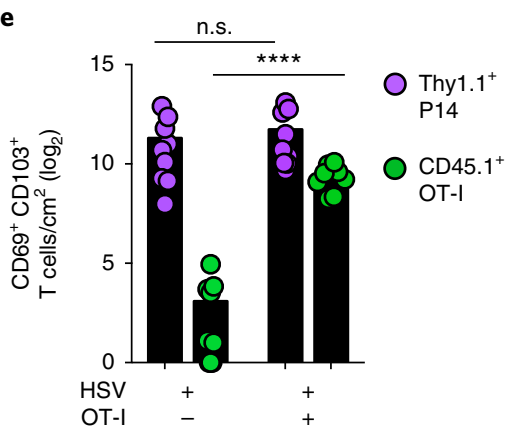

g

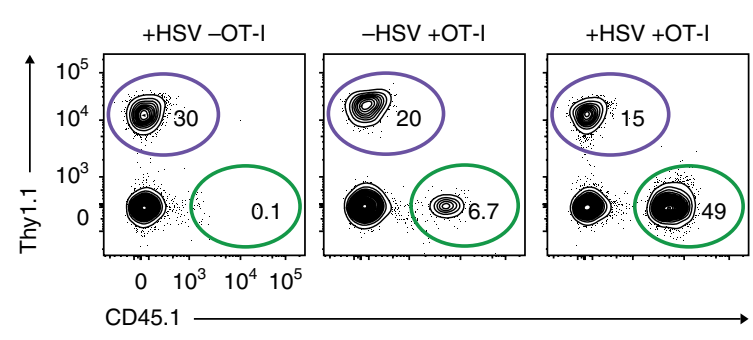

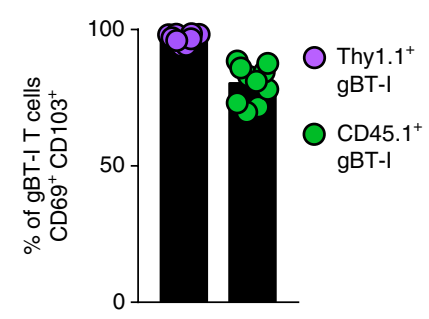

$\mathbf{f}$
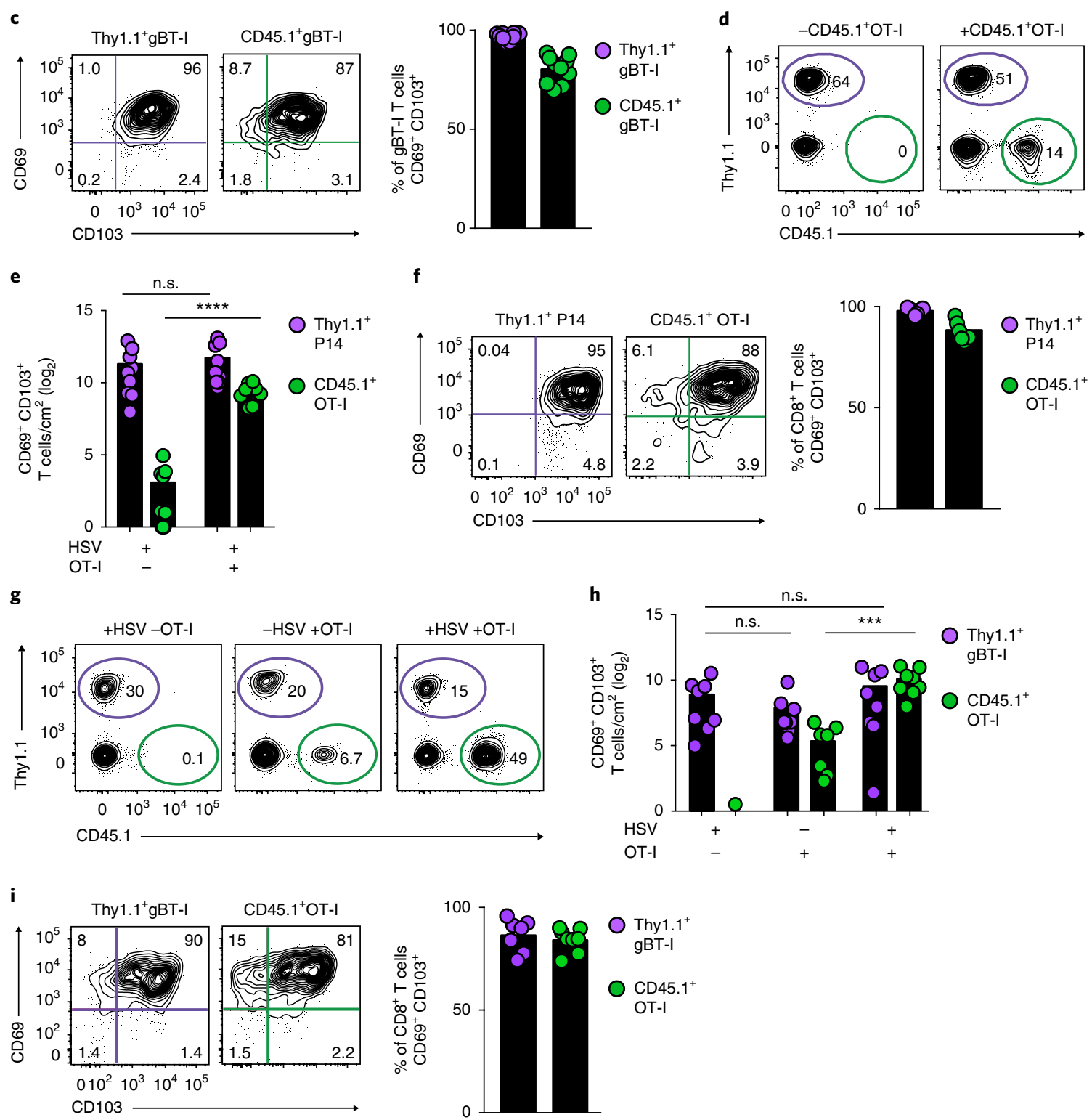

Fig. $5 \mid T_{\text {CIRCM }}$ cells and bystander $T_{E F F}$ cells generate de novo $T_{R M}$ cells after viral challenge. $\mathbf{a}$, The frequency of Thy $1.1^{+}$gBT-I (DNFB-lodged) and CD45.1 ${ }^{+}$ gBT-I ( $T_{\text {CIRCM }}$-cell-derived) T cells in DNFB-treated skin $>30 \mathrm{~d}$ after HSV infection. b,c, The number of Thy1.1 $1^{+} \mathrm{gBT}-\mathrm{I}$ and $\mathrm{CD} 45.1^{+} \mathrm{gBT}-\mathrm{I} \mathrm{T}_{\mathrm{RM}}$ cells $(\mathbf{b})$ and their CD69 and CD103 expression c in DNFB-treated skin $>30 \mathrm{~d}$ after HSV infection. ${ }^{\star \star \star} P=0.0002$, two-tailed Mann-Whitney test. n.S., not significant. d, The frequency of Thy $1.1^{+}$P14 (DNFB-lodged) and CD45.1+ OT-I ( $\mathrm{T}_{\mathrm{EFF}}$-cell-derived) T cells in DNFB-treated skin $>30 \mathrm{~d}$ after HSV infection. e,f, The number of Thy $1.1^{+}$P14 and CD45.1+ OT-I T $T_{\text {RM }}$ cells (e) and their CD69 and CD103 expression $\mathbf{f}$ in DNFB-treated skin $>30 \mathrm{~d}$ after HSV infection. ${ }^{\star \star \star \star} P<0.0001$. $\mathbf{g}$, The frequency of Thy1.1+ gBT-I (VV-gB, lodged) and CD45.1+ OT-I ( $T_{\text {EFF }}$-cell-derived) T cells in VV-gB-challenged skin $>30 \mathrm{~d}$ after HSV infection. h,i, The number of Thy $1.1^{+}$gBT-I and CD45.1+ OT-I T $\mathrm{RM}$ cells (i) and their CD69 and CD103 expression (h) in VV-gB-challenged skin >30 d after HSV infection. ${ }^{\star \star \star} P=0.0002$, two-tailed Mann-Whitney $U$-test. $(\mathbf{b}, \mathbf{c}, \mathbf{e}, \mathbf{f}, \mathbf{h}, \mathbf{i})$ In bar plots, bars represent the mean, and circles represent individual mice. (a,d,g) Numbers adjacent to outlines indicate the percentage of cells in the gate. (c, $\mathbf{f}, \mathbf{i})$ Numbers in corners indicate the percentage of cells in each quadrant. Data are representative of two experiments with $n=3$ or $5(\mathbf{a}), 4$ or $5(\mathbf{d})$, or $4(\mathbf{g})$ mice per group, or are pooled from two experiments with $n=6$ or $10(\mathbf{b}, \mathbf{c}), 9(\mathbf{e}, \mathbf{f})$, or $8(\mathbf{h}, \mathbf{i})$ mice per group. 

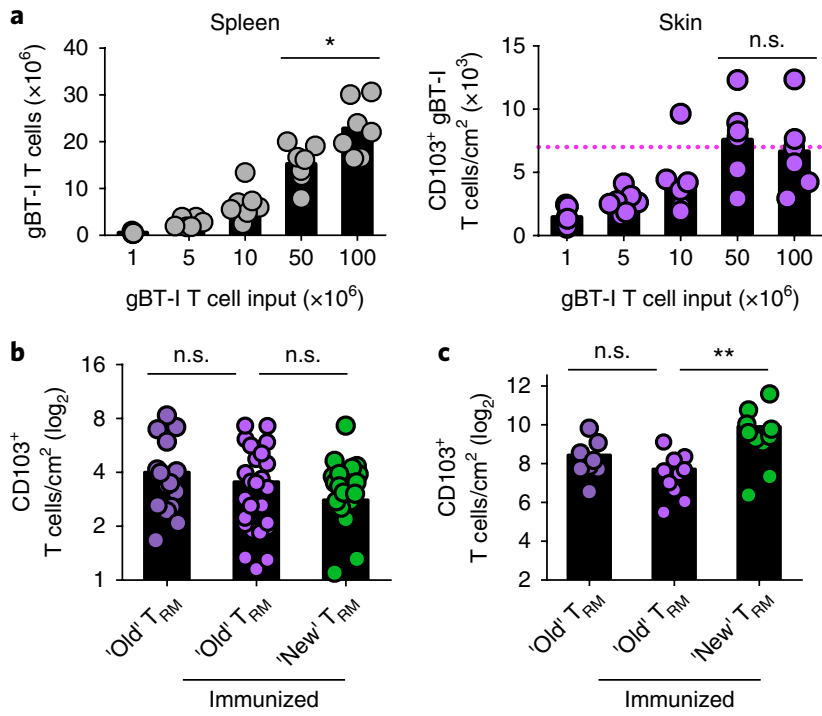

Fig. 6 | De novo-generated $T_{R M}$ cells do not displace pre-existing $T_{R M}$ cells in skin. a, Mice were seeded with $1 \times 10^{6}$ to $100 \times 10^{6} \mathrm{CD} 45.1^{+} \mathrm{gBT}-\mathrm{I}$ $\mathrm{T}_{\mathrm{EFF}}$ cells and treated with DNFB. Shown are the numbers of gBT-I T cells in the spleen and $\mathrm{CD}_{103^{+}} \mathrm{gBT}-\mathrm{I} \mathrm{T}_{\mathrm{RM}}$ cells in DNFB-treated skin $>30 \mathrm{~d}$ after treatment. ${ }^{\star} P=0.0262$; n.s., not significant; two-tailed Mann-Whitney test. b, The number of 'old' (DNFB-lodged) EGFP+ OT-I T RM cells (generated from $50 \times 10^{6}$ input EGFP+ OT-I T EFF cells) and 'new' prime-boosted CD45.1 ${ }^{+}$ gBT-I T cells in DNFB-treated skin of flu-immunized mice $>30 \mathrm{~d}$ after the final immunization, or in non-immunized mice. n.s., not significant; Kruskal-Wallis test with Dunn's multiple comparisons. c, The number of DNFB-lodged CD45.1+ gBT-I T RM $_{1}$ cells and VV-OVA-primed EGFP+ OT-I $T_{R M}$ cells in DNFB-treated skin $>25 \mathrm{~d}$ after the final contralateral V V-OVA immunization, or in non-immunized mice. n.s., not significant; ${ }^{\star \star} P=0.0098$; Kruskal-Wallis test with Dunn's multiple comparisons. In all panels, bars represent the mean, and circles represent individual mice. Data are pooled from two experiments with $n=6$ or 7 mice per group (a), $n=18-25$ mice per group (b) or $n=9$ or 10 mice $(\mathbf{c})$.

novo differentiation of restimulated $\mathrm{T}_{\mathrm{CIRCM}}$ cells into $\mathrm{T}_{\mathrm{RM}}$ cells contribute independently to the maintenance or expansion of the $\mathrm{T}_{\mathrm{RM}}$ cell pool after secondary infection.

We then sought to determine whether $\mathrm{CD}^{+} \mathrm{T}_{\mathrm{EFF}}$ cells of an unrelated specificity would give rise to $T_{R M}$ cells in HSV-infected skin that contained pre-existing $\mathrm{T}_{\mathrm{RM}}$ cells. We depleted Thy $1.1^{+} \mathrm{P} 14$ $\mathrm{T}_{\text {CIRCM }}$ cells in mice with DNFB-recruited skin-lodged non-HSVspecific Thy1.1+ $\mathrm{P} 14 \mathrm{~T}_{\mathrm{RM}}$ cells by administering anti-Thy1.1, and then infected them with HSV above the DNFB patch $>7 \mathrm{~d}$ later. Mice received adoptive transfers of in vitro-activated CD45.1 $1^{+}$OT-I $\mathrm{T}_{\mathrm{EFF}}$ cells and were examined after $30 \mathrm{~d}$ (Supplementary Fig. 5b). HSV infection resulted in recruitment of non-HSV-specific CD $45.1^{+} \mathrm{OT}-\mathrm{I}$ $\mathrm{T}_{\mathrm{EFF}}$ cells into DNFB-treated skin (Fig. 5d,e), and these bystander CD $45.1^{+}$OT-I $\mathrm{T}_{\mathrm{EFF}}$ cells had converted to a CD69 ${ }^{+} \mathrm{CD} 103^{+} \mathrm{T}_{\mathrm{RM}}$ cell phenotype (Fig. 5f). The number of pre-existing Thy1.1 $1^{+} \mathrm{P} 14 \mathrm{~T}_{\mathrm{RM}}$ cells in the skin was not affected by CD45.1 ${ }^{+}$OT-I $\mathrm{T}_{\mathrm{EFF}}$ cell transfer, despite de novo OT-I $\mathrm{T}_{\mathrm{RM}}$ cell formation (Fig. 5e).

Because the presence of local antigen in tissue can influence the formation of $\mathrm{T}_{\mathrm{RM}}$ cells ${ }^{29-31}$, we next examined the recall of $\mathrm{T}_{\mathrm{RM}}$ cells induced by direct skin infection with a virus rather than by DNFB recruitment. We transferred Thy $1.1^{+}$gBT-I $\mathrm{T}_{\mathrm{N}}$ cells into mice, infected the mice on the lower flank skin with VV-gB to generate a population of Thy $1.1^{+}$gBT-I $\mathrm{T}_{\mathrm{RM}}$ cells, and subsequently administered anti-Thy1.1 to deplete Thy1.1 ${ }^{+}$gBT-I $\mathrm{T}_{\text {CIRCM }}$ cells. More than $30 \mathrm{~d}$ after $\mathrm{VV}$-gB infection and $>7 \mathrm{~d}$ after $\mathrm{T}_{\text {CIRCM }}$ depletion, we challenged the mice with HSV above the initial VV-gB scarification site and transferred in vitro-activated CD45. $1^{+}$nonspecific OT-I $\mathrm{T}_{\mathrm{EFF}}$ cells into them (Supplementary Fig. 5c). We detected both Thy $1.1^{+}$ gBT-I $\mathrm{T}_{\mathrm{RM}}$ cells generated in response to $\mathrm{VV}-\mathrm{gB}$ infection and bystander CD45.1 $1^{+}$OT-I $\mathrm{T}_{\mathrm{RM}}$ cells in skin at the previously infected VV-gB site $>30 \mathrm{~d}$ after HSV challenge (Fig. $5 \mathrm{~g}-\mathrm{i}$ ). The number of Thy1.1 ${ }^{+}$gBT-I $\mathrm{T}_{\mathrm{RM}}$ cells in VV-gB-challenged skin was not changed after HSV infection or by the transfer of bystander OT-I $\mathrm{T}_{\mathrm{EFF}}$ cells, despite the induction of substantial OT-I $\mathrm{T}_{\mathrm{RM}}$ cells after HSV infection (Fig. 5h), which suggests that virally induced $T_{R M}$ cells are also stably maintained after reinfection. Further, to examine recall responses to HSV in the absence of antibody-mediated protection, we infected B-cell-deficient $(\mu \mathrm{MT}) \mathrm{Ighm}^{-/-}$mice given adoptive transfer of Thy $1.1^{+}$gBT-I T $\mathrm{N}_{\mathrm{N}}$ cells with HSV on the lower flank and then treated them with anti-Thy1.1 $>30 \mathrm{~d}$ after infection to induce $\mathrm{T}_{\text {CIRCM }}$ cell depletion. Ten days after $\mathrm{T}_{\text {CIRCM }}$ cell depletion, we rechallenged the mice with HSV on the upper flank and administered in vitro-activated CD45.1+ OT-I $\mathrm{T}_{\mathrm{EFF}}$ cells (Supplementary Fig. 5d). We detected Thyl.1 ${ }^{+}$gBT-I $\mathrm{T}_{\mathrm{RM}}$ cells generated by the primary HSV infection in post-lesional skin $>30 \mathrm{~d}$ after HSV rechallenge (Supplementary Fig. 5e). Previously infected skin also contained CD 45.1 $1^{+}$OT-I $\mathrm{T}_{\mathrm{EFF}}$ cells that had converted into CD69+CD103 ${ }^{+} \mathrm{T}_{\mathrm{RM}}$ cells, without any effect on the numbers of Thy1.1 ${ }^{+}$gBT-I $\mathrm{T}_{\mathrm{RM}}$ cells (Supplementary Fig. 5e). Combined, these results show that preexisting and incoming $\mathrm{T}_{\mathrm{RM}}$ cell populations of identical or different specificities can be maintained and established concomitantly, and do not outcompete one another in the context of local infection.

New $T_{R M}$ cells minimally dislodge pre-existing $T_{R M}$ cells. To determine whether there is a maximal capacity for $\mathrm{T}_{\mathrm{RM}}$ cell generation in the skin, we transferred increasing numbers of CD45.1 $1^{+}$gBT-I $\mathrm{T}_{\mathrm{EFF}}$ cells into mice and induced $\mathrm{T}_{\mathrm{RM}}$ cell lodgment in the skin with DNFB. Although $\mathrm{T}$ cell input in the range of $1 \times 10^{6}$ to $100 \times 10^{6}$ gBT-I $\mathrm{T}_{\mathrm{EFF}}$ cells resulted in increasing numbers of splenic gBT-I T cells (Fig. 6a), the number of skin gBT-I $\mathrm{T}_{\mathrm{RM}}$ cells plateaued after input of $50 \times 10^{6}$ to $100 \times 10^{6} \mathrm{gBT}$-I T cells (Fig. $6 \mathrm{a}$ ), which indicated that a limited number of $\mathrm{T}_{\mathrm{RM}}$ cells could be generated in the skin, at least during a single inflammatory response. To test whether subsequent responses could add to the $\mathrm{T}_{\mathrm{RM}}$ cell pool, we transferred CD $45.1^{+}$gBT-I $\mathrm{T}_{\mathrm{N}}$ cells into mice carrying DNFB-induced skin $\mathrm{EGFP}^{+}$OT-I $\mathrm{T}_{\mathrm{RM}}$ cells. After $>30 \mathrm{~d}$, we subjected the mice to prime-boost immunization with i.v.-transferred gB-pulsed dendritic cells followed by subcutaneous and intranasal infection with recombinant influenza viruses, which results in widespread generation of skin $\mathrm{T}_{\mathrm{RM}}$ cells ${ }^{31}$. We left a separate cohort of mice untreated (Supplementary Fig. 6a). More than $30 \mathrm{~d}$ after influenza virus infection, we detected a pool of newly generated ('new') CD45.1 ${ }^{+}$ gBT-I $T_{R M}$ cells of a different $T$ cell receptor specificity in DNFBtreated skin that also contained 'old' $\mathrm{EGFP}^{+} \mathrm{OT}-\mathrm{I} \mathrm{T}_{\mathrm{RM}}$ cells (Fig. $6 \mathrm{~b})$. The generation of new $\mathrm{T}_{\mathrm{RM}}$ cells by multiple-route prime-boost immunization allowed us to assess whether dislodgment of preexisting $\mathrm{T}_{\mathrm{RM}}$ cells occurred in the absence of perturbation to the skin tissue itself. We detected minimal numerical decay of DNFBinduced 'old' skin $\mathrm{EGFP}^{+} \mathrm{OT}-\mathrm{I} \mathrm{T}_{\mathrm{RM}}$ cells in prime-boost-immunized mice compared with that in control mice that were not subjected to prime-boost immunization (Fig. 6b), which indicated that de novo formation of $\mathrm{T}_{\mathrm{RM}}$ cells with different specificities occurred without displacement of pre-existing $\mathrm{T}_{\mathrm{RM}}$ cells in the tissue. Moreover, when DNFB-treated mice carrying 'old' CD $45.1^{+} \mathrm{gBT}-\mathrm{I} \mathrm{T}_{\mathrm{RM}}$ cells received adoptively transferred EGFP' OT-I $\mathrm{T}_{\mathrm{N}}$ cells and 'new' $\mathrm{T}_{\mathrm{RM}}$ cell formation was induced via multiple skin immunizations (epicutaneous infection with VV-OVA contralateral to DNFB-treated skin followed by secondary VV-OVA infection at an unrelated skin site) (Supplementary Fig. 6b), the number of pre-existing CD $45.1^{+}$gBT-I $\mathrm{T}_{\mathrm{RM}}$ cells in the skin remained constant compared with that in nonimmunized mice (Fig. 6c). Collectively, these findings highlight the exceptional stability of skin $\mathrm{T}_{\mathrm{RM}}$ cell populations after rechallenge. 


\section{Discussion}

Here we found that $T_{R M}$ cells respond in an antigen-specific manner, proliferate and survive after local restimulation, and are not dislodged by newly generated $\mathrm{T}_{\mathrm{RM}}$ cells. This has important implications for understanding how immune memory is maintained in peripheral tissues. We show that $\mathrm{T}_{\mathrm{RM}}$-cell-mediated protection is directly linked to the density of $\mathrm{T}_{\mathrm{RM}}$ cells in the skin. This finding was predicted by mathematical models that showed an inverse correlation between the number of $\mathrm{CD}^{+} \mathrm{T}$ cells in the genital mucosa after HSV reactivation and the severity of disease ${ }^{32}$. We observed that $\mathrm{T}_{\mathrm{RM}}$ cells that interacted with virus-infected cells decelerated and were restimulated, whereas $T_{R M}$ cells in nearby uninfected epidermis continued to exhibit random migration. Our imaging did not reveal any obvious attraction of $\mathrm{T}_{\mathrm{RM}}$ cells to virally infected cells, which suggests that $T_{R M}$ cells need to be in the right place at the right time to protect against infection. Consequently, it may take hours to days for epidermal $\mathrm{T}_{\mathrm{RM}}$ cells to chance upon infected cells, which highlights the importance of $\mathrm{T}_{\mathrm{RM}}$ cell density for protection. We found that $\mathrm{T}_{\mathrm{RM}}$ cells were able to protect against local infection independently of $\mathrm{T}_{\text {CIRCM }}$ cells, although the mechanism through which $\mathrm{T}_{\mathrm{RM}}$ cells execute protection is unclear. It has been shown that $\mathrm{T}_{\mathrm{RM}}$ cells can directly kill infected cell targets ${ }^{33}$. Although we observed skin $T_{R M}$ cells engaging virally infected cells, we were unable to regularly document killing of infected targets by $\mathrm{CD}^{+}$ $\mathrm{T}$ cells in the skin (data not shown). It is possible that the density of $\mathrm{T}_{\mathrm{RM}}$ cells inversely regulates the recruitment of $\mathrm{T}$ cells from the circulation, as near-sterile immunity induced by local $\mathrm{T}_{\mathrm{RM}}$ cells might negate the need to recruit large numbers of $\mathrm{T}_{\mathrm{CIRCM}}$ cells and reduce inflammation.

$\mathrm{T}_{\mathrm{RM}}$ cells proliferated in response to antigen, yet numbers of secondary $\mathrm{T}_{\mathrm{RM}}$ cells in the absence of $\mathrm{T}_{\mathrm{CIRCM}}$ cells did not markedly increase. Skin $\mathrm{T}_{\mathrm{RM}}$ cell populations seemed to maintain their stability by balancing cell death with proliferation, as we observed increased annexin $\mathrm{V}$ staining of skin $\mathrm{T}_{\mathrm{RM}}$ cells after viral recall. Restimulated $\mathrm{T}_{\mathrm{RM}}$ cells did not exit the epidermis even after proliferation, at least within the first $5 \mathrm{~d}$ after reinfection. $\mathrm{T}_{\mathrm{RM}}$ cells survive poorly when removed from tissues ${ }^{33}$ (data not shown), which potentially limits their relocation to other tissues. Collectively, our results indicate that $\mathrm{T}_{\mathrm{RM}}$ cells, at least in the skin, are a durable and autonomous population. It will, however, be important to ascertain whether $T_{R M}$ cells in other organs are similarly tissue restricted after reactivation, particularly in tissues such as the lungs, where local $\mathrm{T}_{\mathrm{RM}}$ cell maintenance relies on constant replenishment from circulating cells ${ }^{34}$.

We show that $\mathrm{T}_{\text {CIRCM }}$ cells and $\mathrm{T}_{\mathrm{EFF}}$ cells are recruited into the skin after pathogen re-encounter; there, some convert into $\mathrm{T}_{\mathrm{RM}}$ cells, thereby adding to the $\mathrm{T}_{\mathrm{RM}}$ cell pool. Our findings suggest that $\mathrm{T}_{\mathrm{RM}}$ cells can be maintained in tissues subject to repeated infections, with unrelated infections unlikely to substantially dislodge $\mathrm{T}_{\mathrm{RM}}$ cells already in the tissue. Such knowledge is of clinical relevance for vaccine strategies that might induce diverse $\mathrm{T}_{\mathrm{RM}}$ cells to protect against multiple diseases. Nonetheless, under conditions where $\mathrm{T}_{\mathrm{RM}}$ cells of certain specificities are undesirable, such as psoriasis in the skin ${ }^{35,36}$, replacing unwelcome $T_{R M}$ cells with desired $T_{R M}$ cell populations may be a challenge.

\section{Methods}

Methods, including statements of data availability and any associated accession codes and refrences, are available at https://doi. org/10.1038/s41590-017-0027-5.

Received: 3 May 2017; Accepted: 28 November 2017; Published online: 08 January 2018

\section{References}

1. Mueller, S. N. \& Mackay, L. K.Tissue-resident memory T cells: local specialists in immune defence. Nat. Rev. Immunol.16, 79-89(2016).
2. Park, C. O. \& Kupper, T. S. The emerging role of resident memory T cells in protective immunity and inflammatory disease. Nat. Med. 21, 688-697 (2015).

3. Casey, K. A. et al. Antigen-independent differentiation and maintenance of effector-like resident memory $\mathrm{T}$ cells in tissues. J. Immunol. 188, 4866-4875 (2012).

4. Steinert, E. M. et al. Quantifying memory CD8 T cells reveals regionalization of immunosurveillance. Cell 161, 737-749 (2015).

5. Sathaliyawala, T. et al. Distribution and compartmentalization of human circulating and tissue-resident memory T cell subsets. Immunity $\mathbf{3 8}$, 187-197 (2013).

6. Mackay, L. K. et al. The developmental pathway for $\mathrm{CD} 103^{+} \mathrm{CD}^{+}$tissueresident memory T cells of skin. Nat. Immunol. 14, 1294-1301 (2013).

7. Mackay, L. K. et al. Hobit and Blimp1 instruct a universal transcriptional program of tissue residency in lymphocytes. Science 352, 459-463 (2016).

8. Wakim, L. M. et al. The molecular signature of tissue resident memory CD8 T cells isolated from the brain. J. Immunol. 189, 3462-3471 (2012).

9. Hombrink, P. et al. Programs for the persistence, vigilance and control of human $\mathrm{CD}^{+}$lung-resident memory T cells. Nat. Immunol. 17, 1467-1478 (2016).

10. Ariotti, S. et al. Skin-resident memory $\mathrm{CD}^{+} \mathrm{T}$ cells trigger a state of tissue-wide pathogen alert. Science 346, 101-105 (2014).

11. Schenkel, J. M. et al. Resident memory CD8 T cells trigger protective innate and adaptive immune responses. Science 346, 98-101 (2014).

12. Schenkel, J. M., Fraser, K. A., Vezys, V. \& Masopust, D. Sensing and alarm function of resident memory $\mathrm{CD}^{+} \mathrm{T}$ cells. Nat. Immunol. 14, 509-513 (2013)

13. Zaid, A. et al. Persistence of skin-resident memory T cells within an epidermal niche. Proc. Natl. Acad. Sci. USA 111, 5307-5312 (2014).

14. Ariotti, S. et al. Tissue-resident memory $C D 8^{+} \mathrm{T}$ cells continuously patrol skin epithelia to quickly recognize local antigen. Proc. Natl. Acad. Sci. USA 109, 19739-19744 (2012).

15. Gebhardt, T. et al. Memory T cells in nonlymphoid tissue that provide enhanced local immunity during infection with herpes simplex virus. Nat. Immunol. 10, 524-530 (2009).

16. Pan, Y. et al. Survival of tissue-resident memory T cells requires exogenous lipid uptake and metabolism. Nature 543, 252-256 (2017).

17. Simmons, A. \& Nash, A. A. Zosteriform spread of herpes simplex virus as a model of recrudescence and its use to investigate the role of immune cells in prevention of recurrent disease. J. Virol. 52, 816-821 (1984).

18. Shin, H. \& Iwasaki, A. A vaccine strategy that protects against genital herpes by establishing local memory T cells. Nature 491, 463-467 (2012).

19. Mackay, L. K. et al. Long-lived epithelial immunity by tissue-resident memory T (TRM) cells in the absence of persisting local antigen presentation. Proc. Natl. Acad. Sci. USA 109, 7037-7042 (2012).

20. Mackay, L. K. et al. T-box transcription factors combine with the cytokines TGF- $\beta$ and IL-15 to control tissue-resident memory T cell fate. Immunity 43 , 1101-1111 (2015).

21. Jiang, $X$. et al. Skin infection generates non-migratory memory $C D 8^{+} T_{R M}$ cells providing global skin immunity. Nature 483, 227-231 (2012).

22. Wu, T. et al. Lung-resident memory CD8 T cells (TRM) are indispensable for optimal cross-protection against pulmonary virus infection. J. Leukoc. Biol. 95, 215-224 (2014).

23. Zens, K. D., Chen, J. K. \& Farber, D. L. Vaccine-generated lung tissueresident memory $\mathrm{T}$ cells provide heterosubtypic protection to influenza infection. JCI Insight 1, e85832 (2016).

24. Gebhardt, T. et al. Different patterns of peripheral migration by memory $\mathrm{CD}^{+}$and $\mathrm{CD}^{+} \mathrm{T}$ cells. Nature 477, 216-219 (2011).

25. Zaid, A. et al. Chemokine receptor-dependent control of skin tissue-resident memory T cell formation. J. Immunol. 199, 2451-2459 (2017).

26. Russell, T. A., Stefanovic, T. \& Tscharke, D. C. Engineering herpes simplex viruses by infection-transfection methods including recombination site targeting by CRISPR/Cas9 nucleases. J. Virol. Methods 213, 18-25 (2015).

27. Tomura, M. et al. Monitoring cellular movement in vivo with photoconvertible fluorescence protein "Kaede" transgenic mice. Proc. Natl. Acad. Sci. USA 105, 10871-10876 (2008).

28. Attanasio, J. \& Wherry, E. J. Costimulatory and coinhibitory receptor pathways in infectious disease. Immunity 44, 1052-1068 (2016).

29. Khan, T. N., Mooster, J. L., Kilgore, A. M., Osborn, J. F. \& Nolz, J. C. Local antigen in nonlymphoid tissue promotes resident memory $\mathrm{CD}^{+} \mathrm{T}$ cell formation during viral infection. J. Exp. Med. 213, 951-966 (2016).

30. Muschaweckh, A. et al. Antigen-dependent competition shapes the local repertoire of tissue-resident memory $\mathrm{CD}^{+} \mathrm{T}$ cells. J. Exp. Med. 213, 3075-3086 (2016)

31. Davies, B. et al. Cutting edge: tissue-resident memory $\mathrm{T}$ cells generated by multiple immunizations or localized deposition provide enhanced immunity. J. Immunol. 198, 2233-2237 (2017).

32. Schiffer, J. T. et al. Mucosal host immune response predicts the severity and duration of herpes simplex virus-2 genital tract shedding episodes. Proc. Natl. Acad. Sci. USA 107, 18973-18978 (2010). 
33. Wakim, L. M., Woodward-Davis, A. \& Bevan, M. J. Memory T cells persisting within the brain after local infection show functional adaptations to their tissue of residence. Proc. Natl. Acad. Sci. USA 107, 17872-17879 (2010).

34. Slütter, B. et al. Dynamics of influenza-induced lung-resident memory T cells underlie waning heterosubtypic immunity. Sci. Immunol. 2, 2-11 (2017).

35. Cheuk, S. et al. CD49a expression defines tissue-resident $\mathrm{CD} 8^{+} \mathrm{T}$ cells poised for cytotoxic function in human skin. Immunity 46, 287-300 (2017).

36. Clark, R. A. Skin-resident T cells: the ups and downs of on site immunity. J. Invest. Dermatol. 130, 362-370 (2010).

\section{Acknowledgements}

We thank C. Jones, G. Davey, M. Damtsis and N. Zamudio for technical assistance. S.L.P. was supported by the University of Melbourne (Elizabeth and Vernon Puzey Postgraduate Scholarship). T.G. was supported by a fellowship from the Sylvia and Charles Viertel Charitable Foundation. This work was supported by the National Health and Medical Research Council of Australia (to S.N.M. and L.K.M.) and the Australian Research Council (to S.N.M.)

\section{Author contributions}

S.L.P., A.Z., J.L.H., S.N.C., J.E.P., B.D., Y.O.A., J.L.G., S.N.M. and L.K.M. performed experiments and analyzed data. T.A.R. and D.C.T. provided reagents. S.L.P., A.Z., T.G., F.R.C., W.R.H., S.N.M. and L.K.M. contributed to experimental design. S.L.P., S.N.M. and L.K.M. prepared the manuscript. S.N.M. and L.K.M. led the research program.

\section{Competing interests}

The authors declare no competing financial interests.

\section{Additional information}

Supplementary information is available for this paper at https://doi.org/10.1038/ s41590-017-0027-5.

Reprints and permissions information is available at www.nature.com/reprints. Correspondence and requests for materials should be addressed to S.N.M. or L.K.M. Publisher's note: Springer Nature remains neutral with regard to jurisdictional claims in published maps and institutional affiliations. 


\section{Methods}

Mice and infections. C57BL/6, gBT-I, gBT-I.xB6.SJL-PtprcaPep3b/BoyJ (gBT-I. CD45.1), gBT-I.Thy1.1, gBT-I.ubiquitin-EGFP (gBT-I.EGFP), gBT-I.EGFP. Thy1.1, gBT-I.Kaede, OT-I.EGFP, P14.DsRed, P14.Thy1.1, OT-I.CD45.1 and $\mu \mathrm{MT}$ $\mathrm{Igmh}^{-1-}$ mice were bred in the Department of Microbiology and Immunology, The University of Melbourne. Animal experiments were approved by The University of Melbourne Animal Ethics Committee. gBT-I mice encode a transgene for a T cell receptor that recognizes the HSV-1 glycoprotein $\mathrm{B}(\mathrm{gB})$-derived epitope $\mathrm{gB}_{498-505}{ }^{37}$. Epicutaneous infection by scarification was done with $1 \times 10^{6}$ plaque-forming units (PFU) of HSV-1 KOS, HSV-1 pCmC (HSV-mCherry) ${ }^{26}$ or HSVgDUL47 $\Delta$ YFP (HSV-CFP) ${ }^{38}$ as described ${ }^{39}$, or with recombinant vaccinia viruses expressing $\mathrm{gB}_{498-505}(\mathrm{VV}-\mathrm{gB})^{40}$ or ovalbumin (VV-OVA) ${ }^{41}$. The strains of recombinant influenza virus expressing $\mathrm{gB}$ used were WSN-gB and $\times 31-\mathrm{gB}(\mathrm{H} 1 \mathrm{~N} 1)$ and were administered subcutaneously or intranasally as described ${ }^{31}$. Viral titers were determined in homogenized skin by PFU assay as described ${ }^{15}$.

\section{Adoptive $\mathrm{T}$ cell transfer and DNFB treatment. Transgenic gBT-I, OT-I or} P14 CD8 ${ }^{+} \mathrm{T}$ cells were activated in vitro by incubation for $4-5 \mathrm{~d}$ with $\mathrm{gB}_{498-505}$ (SSIEFARL), OVA (SIINFEKL) or gp33 (KAVYNFATM) peptide-pulsed splenocytes in the presence of recombinant human IL-2 (25 U/mL; PeproTech) as described ${ }^{15}$. Except where indicated, $2 \times 10^{6}$ to $10 \times 10^{6}$ effector gBT-I or OT-I $\mathrm{T}$ cells were adoptively transferred i.v. Mice were shaved and depilated before the application of $15 \mu \mathrm{l}$ of DNFB in acetone and oil (4:1) to a $1.5-\mathrm{cm}^{2}$ area of skin on the day of T cell transfer. Alternatively, $5 \times 10^{4}$ to $1 \times 10^{6}$ naive gBT-I or OT-I T cells were transferred i.v. before infection. For adoptive transfer of $\mathrm{CD}^{+}$memory $\mathrm{T}$ cells, we enriched cells from spleens of HSV-immune mice $>30 \mathrm{~d}$ after infection by staining cell suspensions with anti-CD4 (GK1.5), anti-CD11b (M1/70), anti-F4/80 (F4/80), anti-erythrocyte (TER-119), and anti-I-A/I-E (M5114) monocolonal antibodies (all generated in-house) and then incubating cells with goat anti-rat IgG-coupled magnetic beads (Qiagen) before removing bead-bound cells.

Flow cytometry. We isolated cells from spleen and lymph nodes by grinding organs through a metal mesh to create single-cell suspensions. T cells were isolated from the skin as described ${ }^{19}$. Briefly, skin was incubated in dispase solution $(2.5 \mathrm{mg} / \mathrm{mL}$; Roche) at $37^{\circ} \mathrm{C}$ for $90 \mathrm{~min}$, and the epidermis was separated from the dermis. The dermis was chopped and incubated in collagenase type $3(3 \mathrm{mg} / \mathrm{mL}$; Worthington) at $37^{\circ} \mathrm{C}$ for $30 \mathrm{~min}$, and the epidermis was placed in trypsin-EDTA (Sigma) and incubated at $37^{\circ} \mathrm{C}$ for $30 \mathrm{~min}$. Cells were stained with antibodies, and their expression of phenotypic markers was determined with a BD Fortessa (BD Biosciences) or BD FACSCanto II (BD Biosciences) and analyzed with FlowJo (Treestar). We used the following antibodies: anti-mouse CD45.1 (A20), CD8 $\alpha$ (53-6.7), V 22 (B20.1), CD69 (H1.2F3), CD16/CD32 (2.4G2), and anti-BrdU (B24) from BD Biosciences; antimouse CD45.1 (A20), CD3e (eBio500A2), CD8 $\alpha$ (53-6.7), CD69 (H1.2F3), CD103 (2E7), Ki67 (20Raj1), CD101 (Moushi101), CD244 (eBio244F4), CTLA4 (UC104B9), LAG3 (e9B7W), PD-1 (J43) and TIM-3 (8B.2C12) from eBioscience; and antimouse CD45.2 (104), CD103 (2E7), CD8 $\alpha$ (53-6.7), CD103 (2E7), Thy1.1 (OX-7) and ICOS (C398.4 A) from Biolegend. Live cells were discriminated with a fixable LIVE/DEAD stain (Life Technologies or Biolegend) or by propidium iodide staining. Annexin V staining was carried out with a BD annexin V FITC staining kit according to the manufacturer's instructions. We enumerated cells by adding a known number of calibration particles (BD Biosciences) to each sample before analysis.

Intravital two-photon microscopy. Mice were anesthetized with isoflurane (Cenvet; 2.5\% for induction, 1-1.5\% for maintenance, vaporized at an 80:20 mixture of $\mathrm{O}_{2}$ and air) and then shaved on the left flank and depilated for flank skin imaging as described ${ }^{42}$. Briefly, we made two incisions ( $\sim 15 \mathrm{~mm}$ apart) longitudinally along the left flank, cutting through the dermis, and separated the peritoneum by cutting away the connective tissues underneath the skin. A 18-mm-wide $\times 1$-mm-thick stainless steel platform was inserted under the exposed dermis, which was glued to the platform with Vetbond tissue adhesive $(3 \mathrm{M})$. The edges of the skin were lined with vacuum grease (Dow Corning), upon which a glass coverslip was placed. Imaging was done with an upright LSM710 NLO multiphoton microscope (Carl Zeiss) with a $20 \times / 1.0$ numerical aperture (NA) water-immersion objective enclosed in an environmental chamber that was maintained at $35^{\circ} \mathrm{C}$ with heated air. Fluorescence excitation was provided by a Chameleon Vision II Ti:sapphire laser (Coherent) with dispersion correction and fluorescence emission detected by external non-descanned photomultiplier tubes. We excited EGFP and second-harmonic generation at $920 \mathrm{~nm}$, mCherry at $960-$ $980 \mathrm{~nm}$, Kaede-green at $800 \mathrm{~nm}$, and Kaede-red at $900 \mathrm{~nm}$. For four-dimensional datasets, three-dimensional stacks were captured every $1 \mathrm{~min}$ for at least $30 \mathrm{~min}$. Raw imaging data were then processed with Imaris 8 (Bitplane), and movies were generated in Imaris and composed in After Effects (Adobe).

Intravital imaging analysis. To distinguish gBT-I T cells on the basis of contact with virus-infected keratinocytes, we generated tracks with the Imaris Spot function and rendered mCherry ${ }^{+}$virus-infected cells as a three-dimensional surface. Tracks were computed with a custom-modified version of the script "Surface to Spot Distance" through an XT/Matlab interface (Mathworks). To segregate $\mathrm{T}$ cells in contact with virus, we used the center of each gBT-I T cell and defined contacting cells as cells remaining within $10 \mu \mathrm{m}$ of rendered virus $\left(\mathrm{mCherry}^{+}\right.$or $\left.\mathrm{CFP}^{+}\right)$for at least $5 \mathrm{~min}$. Statistical values for mean track speed and mean track displacement length were extracted from Imaris software. Statistical significance was determined by Mann-Whitney $U$-test.

Depletion of circulating Thy1.1+ gBT-I T cells. More than $20 \mathrm{~d}$ after transfer of activated Thy $1.1^{+}$gBT-I cells and DNFB treatment, mice were injected i.p. 1-3 times with 0.5-4 $\mu \mathrm{g}$ anti-mouse/rat Thy1.1 mAb ( $\alpha$-Thy1.1; clone HIS57; eBioscience) in PBS. Control mice received PBS alone.

In vivo photoconversion of Kaede ${ }^{+}$gBT-I $\mathrm{T}_{\mathrm{RM}}$ cells. Mice containing Kaede ${ }^{+}$ gBT-I $\mathrm{T}_{\mathrm{RM}}$ cells were anesthetized, shaved and depilated, and infected with HSVmCherry. At $2 \mathrm{~d}$ post-infection, we used a 410-nm spot lamp (Dymax Bluewave LED; UV Pacific) to expose mice to $100 \mathrm{~mJ} / \mathrm{cm}^{2}$ violet light for $6 \mathrm{~min}$. Light emitted through an 8-mm-diameter fiber optic guide was mounted at a distance of $4.17 \mathrm{~cm}$ directly above the DNFB patch, and areas around the patch were covered with a double layer of aluminum foil to prevent distal photoconversion. Mice were then imaged by IV-2PM from $94 \mathrm{~h}$ post-infection.

Transcutaneous delivery of gB and OVA peptide. We added $50 \mu \mathrm{g}$ of MHC-Irestricted HSV gB 498-505 (SSIEFARL) or OVA (SIINFEKL) peptides (Genscript) to $100 \mathrm{mg}$ of sorbolene cream and mixed it thoroughly by successive vortexing and short-pulse centrifugation. Mice containing DNFB-recruited lodged $\mathrm{T}_{\mathrm{RM}}$ cells were anesthetized, shaved and depilated, and the peptide-sorbolene mixture was applied directly atop the DNFB patch. The peptide-cream mixture was contained above the skin region by a bandage consisting of an adhesive film (OpSite Flexigrid; Smith \& Nephew) and surgical tape (Micropore tape; $3 \mathrm{M}$ ). For intravital imaging experiments, the mixture was allowed to absorb through the skin for $3 \mathrm{~h}$ before removal of the bandage. For flow cytometry experiments, the peptidesorbolene mixture was applied once per day for $2 \mathrm{~d}$, and mice were bandaged for $24 \mathrm{~h}$ after each application.

In vivo bromodeoxyuridine treatment. Mice were injected i.p. with $2 \mathrm{mg}$ of BrdU per day, with treatment commencing on the day of transcutaneous peptide application or 0-2 d after infection. BrdU incorporation was measured with a BrdU flow kit (BD Biosciences) or FoxP3 staining kit (eBioscience), and where indicated the proportion of $\mathrm{BrdU}^{+}$cells was determined by the Overton method of population comparison ${ }^{42}$ (FlowJo; Treestar), with skin gBT-I T cells from an untreated mouse used as the control population.

Generation and transfer of bone-marrow-derived dendritic cells. We differentiated dendritic cells by culturing C57BL/ 6 bone marrow cells in the presence of $20 \mathrm{ng} / \mathrm{mL}$ GM-CSF and IL- 4 for $7 \mathrm{~d}$. Dendritic cells were matured overnight in the presence of $150 \mathrm{ng} / \mathrm{mL}$ LPS, then pulsed with $1 \mu \mathrm{g} / \mathrm{mL} \mathrm{gB}_{498-505}$ (SSIEFARL) peptide for $45 \mathrm{~min}$ before transfer of $2.5 \times 10^{5}$ cells i.v. to recipients.

Statistics and reproducibility. Two-tailed Mann-Whitney $U$-tests, one-way ANOVA with Tukey's multiple comparisons test or Kruskal-Wallis tests with Dunn's multiple comparison test were used where indicated. All proportional numerical values provided in the text are written as the mean \pm s.e.m. All statistical analyses were done in Prism 7.0 (Graphpad). All experiments were performed at least two times, with similar results obtained each time.

Life Sciences Reporting Summary. Further information on experimental design and reagents is available in the Life Sciences Reporting Summary.

Data availability. Publically available source data were not used in this study. Data supporting the findings of this study are available from the corresponding authors upon request.

\section{References}

37. Mueller, S. N., Heath, W., McLain, J. D., Carbone, F. R. \& Jones, C. M. Characterization of two TCR transgenic mouse lines specific for herpes simplex virus. Immunol. Cell. Biol. 80, 156-163 (2002).

38. Macleod, B. L. et al. Distinct APC subtypes drive spatially segregated CD4+ and $\mathrm{CD}^{+}$T-cell effector activity during skin infection with HSV-1. PLoS. Pathog. 10, el004303 (2014)

39. van Lint, A. et al. Herpes simplex virus-specific $\mathrm{CD} 8^{+} \mathrm{T}$ cells can clear established lytic infections from skin and nerves and can partially limit the early spread of virus after cutaneous inoculation. J. Immunol. 172, 392-397 (2004).

40. Blaney, J. E. Jr. et al. Immunization with a single major histocompatibility complex class I-restricted cytotoxic T-lymphocyte recognition epitope of herpes simplex virus type 2 confers protective immunity. J. Virol. 72, 9567-9574 (1998)

41. Restifo, N. P. et al. Antigen processing in vivo and the elicitation of primary CTL responses. J. Immunol. 154, 4414-4422 (1995).

42. Overton, W. R. Modified histogram subtraction technique for analysis of flow cytometry data. Cytometry 9, 619-626 (1988). 


\section{Life Sciences Reporting Summary}

Nature Research wishes to improve the reproducibility of the work we publish. This form is published with all life science papers and is intended to promote consistency and transparency in reporting. All life sciences submissions use this form; while some list items might not apply to an individual manuscript, all fields must be completed for clarity.

For further information on the points included in this form, see Reporting Life Sciences Research. For further information on Nature Research policies, including our data availability policy, see Authors \& Referees and the Editorial Policy Checklist.

\section{- Experimental design}

\section{Sample size}

Describe how sample size was determined.

\section{Data exclusions}

Describe any data exclusions.

\section{Replication}

Describe whether the experimental findings were reliably reproduced.

\section{Randomization}

Describe how samples/organisms/participants were allocated into experimental groups.

\section{Blinding}

Describe whether the investigators were blinded to group allocation during data collection and/or analysis.
No statistical test was used to pre-determine sample size.

For Fig. $2 b$, The anterior prostate was excluded from the analysis due to cystic lesions after 12-week time point.

The number of repeats for experiments was described in corresponding figure legends. Only successfully replicated/reproduced experiments were reported.

Genotypes and ages of mice are known to investigators. No preestablished selection criteria for mice were used. All mice with desired genotypes at appropriate ages in corresponding cages were all used and randomized to either the control or experimental group.

The investigators were not blinded to allocation during experiments and outcome assessment.

Note: all studies involving animals and/or human research participants must disclose whether blinding and randomization were used.

\section{Statistical parameters}

For all figures and tables that use statistical methods, confirm that the following items are present in relevant figure legends (or the Methods section if additional space is needed).

$\mathrm{n} / \mathrm{a} \mid$ Confirmed

Х The exact sample size $(n)$ for each experimental group/condition, given as a discrete number and unit of measurement (animals, litters, cultures, etc.) A description of how samples were collected, noting whether measurements were taken from distinct samples or whether the same sample was measured repeatedly.

A statement indicating how many times each experiment was replicated

The statistical test(s) used and whether they are one- or two-sided (note: only common tests should be described solely by name; more complex techniques should be described in the Methods section)

A description of any assumptions or corrections, such as an adjustment for multiple comparisons

The test results (e.g. $p$ values) given as exact values whenever possible and with confidence intervals noted

A summary of the descriptive statistics, including central tendency (e.g. median, mean) and variation (e.g. standard deviation, interquartile range) Clearly defined error bars 
Policy information about availability of computer code

\section{Software}

Describe the software used to analyze the data in this study.

GraphPad and R were used to perform general statistical analysis.

For all studies, we encourage code deposition in a community repository (e.g. GitHub). Authors must make computer code available to editors and reviewers upon

request. The Nature Methods guidance for providing algorithms and software for publication may be useful for any submission.

\section{- Materials and reagents}

Policy information about availability of materials

\section{Materials availability}

Indicate whether there are restrictions on availability of unique materials or if these materials are only available for distribution by a

for-profit company.

No unique materials were used.

\section{Antibodies}

Describe the antibodies used and how they were validated for use in the system under study (i.e. assay and species).

A detailed description of antibodies used, including vendors and catalogue numbers, was provide in Methods, under "Plasmids, reagents and antibodies" section. Antibodies were validated by gene silencing and/or overexpression, and by other published studies.

\section{Eukaryotic cell lines}

a. State the source of each eukaryotic cell line used.

All cell lines were obtained from ATCC.

b. Describe the method of cell line authentication used.

All cell lines were purchased directly from ATCC

c. Report whether the cell lines were tested for mycoplasma contamination.

All cell lines were checked for mycoplasma by MycoAlert Mycoplasma Detection Kit (Lonza).

d. If any of the cell lines used in the paper are listed in the database of commonly misidentified cell lines maintained by ICLAC, provide a scientific rationale for their use.

\section{- Animals and human research participants}

Policy information about studies involving animals; when reporting animal research, follow the ARRIVE guidelines

\section{Description of research animals}

Provide details on animals and/or animal-derived materials used in the study.

Policy information about studies involving human research participants

\section{Description of human research participants}

Describe the covariate-relevant population characteristics of the human research participants.
Methods/Murine models

Methods/TMA analysis and Supplementary Table 1 